\title{
The Relationship of the North American Monsoon to Tropical and North Pacific Sea Surface Temperatures as Revealed by Observational Analyses
}

\author{
Christopher L. Castro, Thomas B. McKee, and Roger A. Pielke Sr. \\ Department of Atmospheric Science, Colorado State University, Fort Collins, Colorado
}

(Manuscript received 18 April 2000, in final form 27 June 2001)

ABSTRACT

\begin{abstract}
The North American monsoon is a seasonal shift of upper- and low-level pressure and wind patterns that brings summertime moisture into the southwest United States and ends the late spring wet period in the Great Plains. The interannual variability of the North American monsoon is examined using the NCEP-NCAR reanalysis (1948-98). The diurnal and seasonal evolution of 500-mb geopotential height, integrated moisture flux, and integrated moisture flux convergence are constructed using a 5-day running mean for the months May through September. All of the years are used to calculate an average daily $\mathrm{Z}$ score that removes the diurnal, seasonal, and intraseasonal variability. The 30-day average $\mathrm{Z}$ score centered about the date is correlated with Pacific sea surface temperature anomaly (SSTA) indices associated with the El Niño-Southern Oscillation (ENSO) and the North Pacific oscillation (NPO). These indices are Niño-3, a North Pacific index, and a Pacific index that combines the previous two. Regional time-evolving precipitation indices for the Southwest and Great Plains, which consider the total number of wet or dry stations in a region, are also correlated with the SSTA indices. The use of nonnormally distributed point source precipitation data is avoided.

Teleconnections are computed relative to the climatological evolution of the North American monsoon, rather than to calendar months, thus more accurately accounting for the climatological changes in the large-scale circulation. Tropical and North Pacific SSTs are related to the occurrence of the Pacific Transition and East Pacific teleconnection patterns, respectively, in June and July. A high (low) NPO phase and El Niño (La Niña) conditions favor a weaker (stronger) and southward (northward) displaced monsoon ridge. These teleconnection patterns affect the timing and large-scale distribution of monsoon moisture. In the Great Plains, the spring wet season is lengthened (shortened) and early summer rainfall and integrated moisture flux convergence are above (below) average. In the Southwest, monsoon onset is late (early) and early summer rainfall and integrated moisture flux convergence are below (above) average. Relationships with Pacific SSTA indices decay in the later part of the monsoon coincident with weakening of the jet stream across the Pacific and strengthening of the monsoon ridge over North America. The most coherent summer climate patterns occur over the entire western United States when the Pacific index is substantially high or low, such as during the Midwest flood of 1993 and drought of 1988. The Pacific index in spring is a good predictor of early summer height anomalies over the western United States when the time evolution of the North Pacific SST dipole is considered.
\end{abstract}

\section{Introduction}

The western United States is particularly sensitive to interannual variability of summer climate. In the most arid regions of the southwest United States, this variability can be larger than the mean summer rainfall itself (Higgins et al. 1998). Climate and weather extremes produce unique dangers and their effects vary in scope. Severe weather hazards include high winds, hail, lightning, and tornadoes. Flash flooding arises from individual localized summer thunderstorms with high rainfall rates. These events are common in the Southwest because of its steep terrain and poor soil moisture holding capacity. Sustained summer flood or drought con-

Corresponding author address: Christopher L. Castro, Department of Atmospheric Science, Colorado State University, Fort Collins, CO 80523.

E-mail: chris@atmos.colostate.edu ditions over broad areas, such as the flood of 1993 or the drought of 1988, result from shifts in the large-scale circulation pattern (e.g., Trenberth and Branstator 1992; Bell and Janowiak 1995; Trenberth and Guillemot 1996). Short- or long-term departures from average conditions may adversely affect infrastructure, agricultural production, water supply, and hydroelectric power generation (e.g., Meehl et al. 2000). The sensitivity to these extreme conditions is likely to increase in the next century if the current trends of population growth and rapid development in urban areas continue. There is a critical need to understand the causes of interannual variability so seasonal forecasts can be improved.

The North American Monsoon System (NAMS) is intimately linked to the large-scale distribution of summer moisture in the western United States. Dry midlatitude westerly flow persists until the middle of June. Monsoon onset is associated with a shift in circulation 
in late June or early July, on average. An extension of the Bermuda high retreats west, initiating light easterly flow at middle and upper levels (above $850 \mathrm{mb}$ ) over the southwest United States (Bryson and Lowry 1955; Adams and Comrie 1997; Higgins et al. 1997b). A diurnal surface heat low forms over southwest Arizona and southern California. Two low-level jets (LLJs), the Great Plains LLJ and the Baja LLJ, are active at night and early morning to midday, respectively (Bonner 1968; Douglas 1995; Higgins et al. 1997a).

There is a rapid increase in precipitation that begins in southern Mexico in June, advances northward along the Sierra Madre mountains, and arrives into the southwest United States by early July (Douglas et al. 1993; Adams and Comrie 1997; Higgins et al. 1997a). Moisture for daily NAMS thunderstorms comes from the Gulf of Mexico, Gulf of California, and the eastern Pacific to varying degrees depending on location (Bryson and Lowry 1955; Reitan 1957; Rasmussen 1967; Hales 1972; Brenner 1974; Douglas et al. 1993; Schmitz and Mullen 1996; Adams and Comrie 1997; Higgins et al. 1997b). Most U.S. NAMS studies focus exclusively on the Southwest because of its clear monsoon signature. However, large-scale circulation changes associated with the monsoon are linked with precipitation changes over other regions of North America, most notably a decrease of precipitation in the central United States (Tang and Rieter 1984; Okabe 1995; Higgins et al. 1997b; Barlow et al. 1998). Given this high degree of interconnectedness for the North American summertime circulation, the present study considers summer teleconnections for the United States and Mexico as a whole.

Interannual variability of winter climate in the western United States has a well-established connection to the El Niño-Southern Oscillation (ENSO). Numerous model and observational studies confirm that variations in the location and strength of tropical convection produce coherent teleconnection patterns in the large-scale circulation over North America (e.g., Horel and Wallace 1981; Livezey and Mo 1987). The recognition of these ENSO-associated teleconnections and their associated climate patterns has substantially improved the accuracy of long-range seasonal forecasts for the winter season. El Niño winters are typically dry and warm in the Pacific Northwest and wet in the Southwest. By contrast, La Niña winters are wet in the Pacific Northwest and dry in the Southwest (e.g., Ropelewski and Halpert 1986).

North Pacific SSTs are also important for winter and summer climate in the western United States. Barlow et al. (2000) provide a brief summary of three basic modes of North Pacific SSTs. The first mode is typical of ENSO, with interannual variation in the tropical and extratropical Pacific (e.g., Nitta and Yamada 1989; Zhang et al. 1997). The second mode, referred by various authors as the Pacific decadal oscillation (PDO) or North Pacific oscillation (NPO), is associated with a Pacific SST dipole that varies on a decadal timescale (e.g., Mantua et al. 1997; Minobe 1997; Gurshunov and Barnett 1998). A high (low) NPO phase is characterized by a strong (weak) Aleutian low, a cold (warm) central North Pacific, and a warm (cold) eastern North Pacific. The third mode, or North Pacific mode, is confined to the far North Pacific and also varies on a decadal timescale. While some modeling studies suggest that North Pacific SSTs are primarily a result of ENSO-forced atmospheric variability (e.g., Lau and Nath 1996), others suggest that North Pacific SST variability, particularly the North Pacific mode, is independent of ENSO and maintained by self-sustaining mechanisms (Nakamura et al. 1997). As of yet, it is not clear what the causes of North Pacific SST variability are, and that is not the subject of this paper. Using long-term sea level pressure and daily precipitation data, Gurshunov and Barnett (1998) showed that the NPO modulates the winter ENSO response. ENSO-associated teleconnection patterns and climate anomalies are most likely when El Niño (La Niña) corresponds with its favored NPO phase. Destructive combinations of ENSO and NPO tend to weaken the effects of either mode of influence, resulting in a weak and incoherent climate response. The NPO was in a high phase, on average, from the late 1970s through most of the 1990s, coincident with an increase in frequency of El Niño events.

Several conclusions can be drawn from the previous analyses of North American summertime precipitation (Carleton et al. 1990; Harrington et al. 1992; Bunkers et al. 1996; Gutzler and Preston 1997; Mo et al. 1997; Ting and Wang 1997; Comrie and Glenn 1998; Higgins et al. 1998, 1999; Higgins and Shi 2000). The monsoon ridge position and strength guide the mid- and upperlevel moisture transport. Two configurations of the monsoon ridge exist that can vary in frequency of occurrence either intraseasonally or interannually. In the ridge north configuration, a strong ridge is located over the Great Plains. Upper-level easterlies carry moisture from the Gulf of Mexico south of the ridge. The monsoon arrives early and is wet in the Southwest. The Great Plains are dry on the subsiding branch of the ridge. In the ridge south configuration, a trough occurs in the western United States and the monsoon ridge is weakened and located over northwest Mexico. Westerly upper-level winds over the western United States direct moisture into the Great Plains. The Southwest is dry and monsoon onset is delayed. The relationship of the monsoon ridge configurations to summer moisture transport, precipitation, and wet and dry summers in the central United States is also well established (Mo et al. 1997).

Summer precipitation in the western United States is related to the distribution of Pacific SSTs. The relationship is particularly strong in the Great Plains. Bunkers et al. (1996) found statistically significant above (below) average precipitation anomalies over North and South Dakota during El Niño (La Niña) summers. Ting and Wang (1997) correlated sea surface temperature anom- 
alies (SSTAs) in the Pacific with a precipitation index of Great Plains stations. Using a singular value decomposition technique, they showed that there are two modes of covariation between Pacific SSTs and central U.S. precipitation. Their first mode is primarily a tropical SST mode and related to precipitation over the northern Great Plains (and the Midwest). Their second mode resembles the NPO and is related to precipitation over the southern Great Plains. As a whole, the Great Plains precipitation studies suggest that wet (dry) summers in that region are associated with El Niño (La Niña) and high (low) NPO.

An opposite relationship between Pacific SSTs and NAMS precipitation may exist in the Southwest. Carleton et al. (1990) noted in wet monsoons that east Pacific SSTs off the California coast are cooler than average in summer. In a study using 65 years of monthly precipitation from stations across Arizona and New Mexico, Harrington et al. (1992) found different patterns in summer precipitation for extremes of the Southern Oscillation, with El Niño (La Niña) favoring above-average July precipitation in northeast New Mexico (west-central Arizona). Higgins et al. (1999) correlated JuneSeptember precipitation totals for three monsoon regions in the United States and Mexico with the Southern Oscillation Index (SOI). They found a statistically significant positive (negative) correlation between La Niña (El Niño) and total summer precipitation in southwest Mexico. Higgins et al. (1998) showed that negative SST anomalies in the eastern tropical Pacific during winter and spring are associated with wet monsoons in Arizona and New Mexico. Higgins and Shi (2000) have related NAMS onset and precipitation in the southwest United States to decade-scale fluctuations in North Pacific SSTs associated with the NPO.

In this study, the original hypothesis of Gurshunov and Barnett (1998) is extended to the summer season. We propose a large-scale framework for considering the summer variability: variations in the NAMS caused by the combination of ENSO and North Pacific variability. The detasets and methodology are discussed in sections 2 and 3. Interannual variability of 500-mb geopotential height, atmospheric moisture, and a precipitation index are related to Pacific SSTs in sections 4 and 5. Lagged relationships with Pacific SSTs and Pacific SST evolution are evaluated in section 6. A discussion and summary are presented in sections 7 and 8 . Table 1 is a list of the paper's frequently used acronyms and symbols.

\section{Description of data}

The updated National Centers for Environmental Prediction-National Center for Atmospheric Research (NCEP-NCAR) daily reanalysis is used to evaluate atmospheric circulation and moisture in the western United States. The reanalysis assimilation system is a modified version of the medium-range forecast spectral model with T62 resolution and 28 sigma levels. The NCEP-
TABLE 1 . Frequenly used acronyms and symbols.

\begin{tabular}{ll}
\hline \hline $\begin{array}{l}\text { Acronym } \\
\text { or symbol }\end{array}$ & \\
\hline COADS & Comprehensive Ocean Atmosphere Dataset \\
CNP & Central North Pacific region $\left(26^{\circ}-36^{\circ} \mathrm{N}, 177^{\circ} \mathrm{E}-164^{\circ} \mathrm{W}\right)$ \\
ENSO & El Niño-Southern Oscillation \\
ENP & Eastern North Pacific region $\left(35^{\circ}-50^{\circ} \mathrm{N}, 125^{\circ}-150^{\circ} \mathrm{W}\right)$ \\
EP & East Pacific pattern \\
ITCZ & Intertropical convergence zone \\
LLJ & Low-level jet \\
MF & Integrated moisture flux (sigma levels $14-28)$ \\
MFC & Integrated moisture flux convergence $($ sigma levels $14-$ \\
& 28) \\
NAMS & North American Monsoon System \\
NP & North Pacific sea surface temperature index \\
NPO & North Pacific oscillation \\
P & Combined Pacific sea surface temperature anomaly index \\
PDO & Pacific decadal oscillation \\
PR & Regional precipitation index \\
PT & Pacific Transition pattern \\
$r$ & Correlation coefficient \\
$r^{2}$ & Explained variance \\
SPI & Standardized precipitation index \\
SST & Sea surface temperature \\
SSTA & Normalized sea surface temperature anomaly \\
$\bar{Z}_{\chi(t)}$ & Thirty-day average $Z$ score of reanalysis variable $\chi$ \\
$\Phi_{500}$ & 500-mb geopotential height \\
\hline &
\end{tabular}

NCAR reanalysis incorporates the widest possible array of data sources with advanced quality control and monitoring systems (Kalnay et al. 1996). The study of interannual climate variability is an intended use of longterm reanalyses and the NCEP-NCAR reanalysis has already been used for this purpose in previous work on the NAMS (e.g., Higgins et al. 1998, 1999; Higgins and Shi 2000). In this study we utilize the reanalysis specific humidity $(q)$, surface pressure $\left(p_{s}\right)$, and winds $(\mathbf{v})$ for sigma levels 28-14 (below approximately $400 \mathrm{mb}$ ), and standard pressure level geopotential heights $(\Phi)$ and winds. These reanalysis variables are more reliable, as compared to model parameterized variables like evaporation or precipitation, because they are directly influenced by the original rawinsonde observations (Kalnay et al. 1996). Four times daily data (0000, 0600, 1200, and 1800 UTC) were obtained from the NCAR archives for the months May through September from 1948 to 1998.

The Cooperative Summary of the Day (Coop) data, from the National Climate Data Center, has surface observations for all past and present cooperative sites throughout the United States. Daily precipitation is recorded as the precipitation reading $24 \mathrm{~h}$ ending at the time of observation, read to hundredths of an inch. Trace amounts of precipitation are recorded. Missing precipitation is also recorded or, at some stations, entire months are absent from the record. Daily Coop precipitation data from 1950 to 1995 were obtained for 340 Great Plains stations $\left(37^{\circ}-45^{\circ} \mathrm{N}, 97^{\circ}-105^{\circ} \mathrm{W}\right)$ and 231 Southwest stations $\left(31^{\circ}-39^{\circ} \mathrm{N}, 106^{\circ}-116^{\circ} \mathrm{W}\right)$. The precipitation regions are shown in Fig. 1a. 
a)

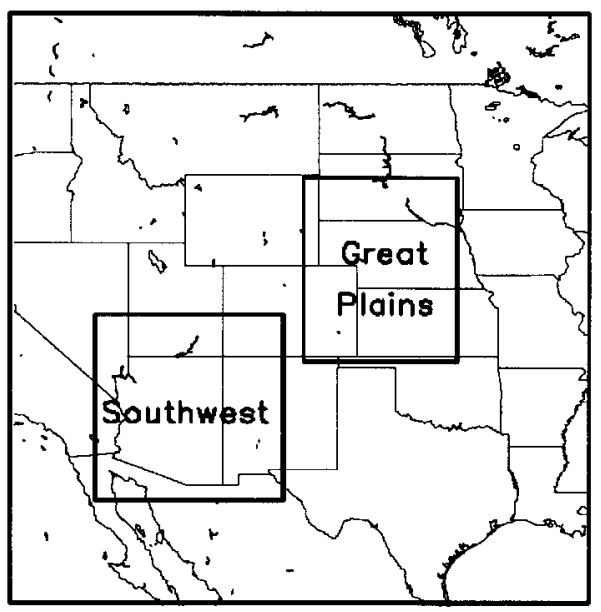

b)

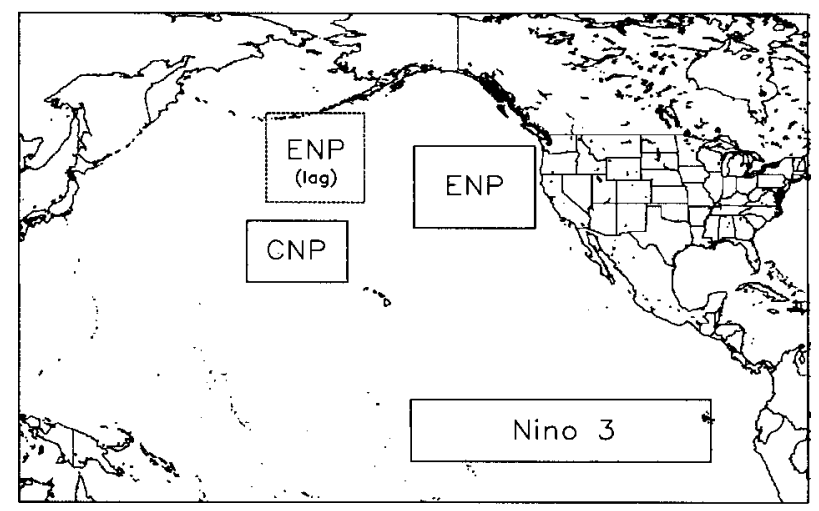

FIG. 1. Regions used to define the (a) Great Plains and Southwest precipitation and (b) Pacific SSTA indices. The ENP (lag) region is used only for lag correlation.

The Comprehensive Ocean Atmosphere Dataset (COADS) contains monthly average SST on a $2^{\circ}$ latitude by $2^{\circ}$ longitude grid from 1854 onward. SST observations are from ship reports and other in situ platforms. A quality control procedure eliminates outlying observations if they fall outside a prescribed number of standard deviations about the smoothed median at a specific location (Slutz et al. 1985). The normalized monthly SSTA from 1950 to 1997 were computed for two regions of the North Pacific, the central North Pacific (CNP; $26^{\circ}-36^{\circ} \mathrm{N}, 177^{\circ} \mathrm{E}-164^{\circ} \mathrm{W}$ ) and the eastern North Pacific (ENP; $35^{\circ}-50^{\circ} \mathrm{N}, 125^{\circ}-150^{\circ} \mathrm{W}$ ). These Pacific regions correspond roughly to the SST dipole in the second mode of Pacific SST found by Ting and Wang (1997) and are correlated $\left(r^{2}>0.25\right)$ with summer precipitation in the Great Plains. We also calculated the SSTAs for a modified ENP region $\left(40^{\circ}-55^{\circ} \mathrm{N}, 180^{\circ}-160^{\circ} \mathrm{W}\right)$ for lag correlation analysis. The traditional Niño-3 normalized SSTA index is used to define ENSO. The Niño indices are readily accessible from the Climate Prediction Cen- ter. The Pacific SSTA regions are shown in Fig. 1b. We also use the Reynolds and Smith (1994) optimally interpolated SST dataset, rather than COADS, to view the time-evolving spatial patterns of SSTAs.

\section{Analysis methods}

Though precipitation is the principal variable of concern, analysis of precipitation throughout the western United States is not straightforward, due to the generally poor spatial and temporal resolution afforded by the available precipitation stations and the nonnormal statistical characteristics of precipitation (e.g., Cowie and McKee 1986). We include here an alternate but complementary approach: analysis of four-times daily reanalysis integrated moisture flux (MF) and moisture flux convergence (MFC). While these variables are also subject to data problems, particularly in Mexico and the Gulf of California (e.g., Barlow et al. 1998), the more large-scale nature of the moisture field relative to precipitation (e.g., Higgins et al. 1997b; Schmitz and Mullen 1996) and the spatial and temporal consistency encouraged by the reanalysis procedures suggests that moisture flux may yield more robust results. At locations throughout the western United States, the daily statistical distribution of MF and MFC is near normal in the summer season (not shown).

The MF and MFC for each analysis time are computed from reanalysis winds (v) and specific humidity $(q)$ on sigma surfaces. These variables are directly related to evaporation $(E)$ and precipitation $(P)$ through the water balance equation (Trenberth and Guillemot 1995; Schmitz and Mullen 1996; Higgins et al. 1997a):

$$
\begin{aligned}
\mathrm{MF} & =\frac{p_{s}}{g} \int_{\sigma_{14}}^{\sigma_{28}}(q \mathbf{v}) d \sigma \\
\mathrm{MFC} & =P-E=-\frac{p_{s}}{g} \int_{\sigma_{14}}^{\sigma_{28}} \boldsymbol{\nabla} \cdot(q \mathbf{v}) d \sigma .
\end{aligned}
$$

The version of the water balance equation used here for MFC omits local storage of water vapor, surface runoff, and ground storage. The MF and MFC for sigma levels 28-14 are computed by a stepwise integration procedure. Since the amount of water vapor at $400 \mathrm{mb}$ is two orders of magnitude less than at the surface, transport of water vapor at upper levels (less than sigma level 14) is assumed negligible (e.g., Higgins et al. 1997b).

Five-day running averages $(\mu)$ and standard deviations $(\sigma)$ of the reanalysis variables are constructed for each day from May through September. Each of the four daily reanalysis times is considered separately. These fields yield an updated 50-yr reanalysis climatology of the height, winds, and moisture fields of the NAMS. This new climatology is similar to more comprehensive NAMS climatologies by Schmitz and Mullen (1996) and Higgins et al. (1997b) based on shorter lengths of record. Some important climatological features include 
the evolution of the monsoon ridge, the seasonal evolution of Great Plains and Baja LLJs, and the diurnal and seasonal evolution of integrated moisture flux convergence. Additional discussion of these aspects of NAMS climatology computed for this work can be found in Castro et al. (2000).

In the same manner as the precipitation studies, the reanalysis variables $(\chi)$ of MF, MFC, and $\Phi_{500}$ are converted to $Z$ scores $\left(Z_{\chi}\right)$ for the four reanalysis times. A spatially varying $Z$ score is defined for each time as

$$
Z_{\chi^{(t)}}=\frac{\chi_{(t)}-\mu_{\chi^{(t)}}}{\sigma_{\chi^{(t)}}}
$$

A time-varying correlation approach is used to relate Pacific SSTs, atmospheric circulation, and atmospheric moisture transport through the course of the summer season. We define two simple SSTA indices. The North Pacific (NP) index is

$$
\mathrm{NP}=\mathrm{ENP}-\mathrm{CNP} .
$$

A Pacific index $(\mathrm{P})$ combines the NP and Niño-3 indices:

$$
\mathrm{P}=\text { Niño-3 }+ \text { ENP }- \text { CNP. }
$$

This new simple $\mathrm{P}$ index is proposed as a way to relate the combination of temporal variability of tropical and North Pacific SSTs. High (low) P roughly corresponds with El Niño (La Niña) and high (low) NPO. The P index weights the influence of the North Pacific more than tropical Pacific SSTs, reflecting the magnitude of correlation between Pacific SSTs and Great Plains summer precipitation found by Ting and Wang (1997).

To isolate the contributions to the explained variance of reanalysis variables from tropical and North Pacific SST, two composites of years are constructed. The approach is similar to Gurshunov and Barnett (1998), except here we compost years by the summer SSTA indices and use a more liberal threshold of SSTA to increase the sample size. For the ENSO composite, the absolute summer average value of Niño-3 is greater than 0.4 . For the North Pacific composite, the summer absolute value of Niño-3 is less than 0.4 and the summer absolute value of the North Pacific index is greater than 0.4. The North Pacific composite is revealing in that it yields the relationship between the NAMS and North Pacific SSTs in ENSO-neutral years. Using these criteria, we obtain 25 years for the ENSO subset and 16 years for the North Pacific subset (see Table 2). The 30day average $Z$ score of the reanalysis variable centered on the date $\left(\bar{Z}_{\chi(t)}\right)$ is correlated with the time-coincident value of the Niño-3 index for the years in the ENSO composite and the NP index for the years of the North Pacific composite.

To evaluate statistical significance, we use the field significance test of Livezey and Chen (1983) as described in Wilks (1995). The effective degrees of freedom $(n)$ for the data at each spatial point is determined as
TABLE 2. Average summer (Jun/Jul/Aug-JJA) values of Pacific

\begin{tabular}{|c|c|c|c|c|}
\hline Year & Niño-3 & NP index & $P$ index & Composite \\
\hline 1950 & -0.33 & 1.26 & 0.92 & NP \\
\hline 1951 & 0.87 & 2.68 & 3.55 & ENSO \\
\hline 1952 & -0.20 & -1.14 & -1.34 & NP \\
\hline 1953 & 0.57 & -1.23 & -0.66 & ENSO \\
\hline 1954 & -0.93 & -1.07 & -2.00 & ENSO \\
\hline 1955 & -0.63 & -1.66 & -2.30 & ENSO \\
\hline 1956 & -0.38 & -0.63 & -1.01 & NP \\
\hline 1957 & 1.27 & 0.00 & 1.26 & ENSO \\
\hline 1958 & 0.36 & 2.86 & 3.23 & NP \\
\hline 1959 & -0.34 & -0.31 & -0.65 & \\
\hline 1960 & -0.03 & -0.90 & -0.94 & NP \\
\hline 1961 & -0.20 & -1.52 & -1.72 & NP \\
\hline 1962 & -0.04 & 0.88 & 0.84 & NP \\
\hline 1963 & 0.87 & 1.12 & 2.00 & ENSO \\
\hline 1964 & -0.87 & -1.32 & -2.19 & ENSO \\
\hline 1965 & 1.27 & 0.90 & 2.17 & ENSO \\
\hline 1966 & 0.01 & -0.21 & -0.20 & \\
\hline 1967 & -0.14 & 2.00 & 1.85 & NP \\
\hline 1968 & 0.32 & -0.29 & 0.02 & \\
\hline 1969 & 0.69 & 0.46 & 1.15 & ENSO \\
\hline 1970 & -1.17 & -0.85 & -2.02 & ENSO \\
\hline 1971 & -0.45 & -1.39 & -1.84 & ENSO \\
\hline 1972 & 1.66 & 0.79 & 2.46 & ENSO \\
\hline 1973 & -0.98 & -1.98 & -2.96 & ENSO \\
\hline 1974 & 0.03 & -0.93 & -0.89 & NP \\
\hline 1975 & -0.72 & 0.09 & -0.62 & ENSO \\
\hline 1976 & 0.86 & -1.83 & -0.96 & ENSO \\
\hline 1977 & 0.06 & 0.26 & 0.32 & \\
\hline 1978 & -0.47 & -0.20 & -0.68 & ENSO \\
\hline 1979 & 0.30 & 2.13 & 2.43 & NP \\
\hline 1980 & 0.27 & 0.36 & 0.63 & \\
\hline 1981 & -0.33 & 0.53 & 0.20 & NP \\
\hline 1982 & 1.25 & 0.64 & 1.89 & ENSO \\
\hline 1983 & 1.50 & -1.10 & 0.40 & ENSO \\
\hline 1984 & -0.50 & -0.99 & -1.49 & ENSO \\
\hline 1985 & -0.57 & -0.30 & -0.87 & ENSO \\
\hline 1986 & 0.20 & 0.78 & 0.98 & NP \\
\hline 1987 & 1.69 & -1.33 & 0.35 & ENSO \\
\hline 1988 & -1.62 & -3.47 & -5.09 & ENSO \\
\hline 1989 & -0.10 & -0.25 & -0.35 & \\
\hline 1990 & 0.23 & 0.08 & 0.31 & \\
\hline 1991 & 0.99 & -0.20 & 0.78 & ENSO \\
\hline 1992 & 0.20 & 2.93 & 3.13 & NP \\
\hline 1993 & 0.48 & 1.68 & 2.16 & ENSO \\
\hline 1994 & -0.02 & 0.45 & 0.42 & NP \\
\hline 1995 & -0.18 & 0.19 & 0.01 & NP \\
\hline 1996 & -0.14 & 0.68 & 0.53 & NP \\
\hline 1997 & 2.65 & 1.36 & 4.01 & ENSO \\
\hline
\end{tabular}
SSTA indices (1950-97). Years of ENSO and North Pacific composites identified.

$$
n=\frac{N}{\tau}
$$

where $N$ is the total number of days from 15 May through 15 September (123) multiplied by the number of years in used in the particular correlation analysis. The $\tau$ value for each point is computed as

$$
\tau=1+2 \sum_{i=1}^{K} C_{1}(i \Delta t) C_{2}(i \Delta t) \Delta t
$$

where $C_{1}(i \Delta t)$ is the autocorrelation of $\bar{Z}_{\chi(t)}$ at lag $i \Delta t$, $C_{2}(i \Delta t)$ is the autocorrelation of the particular SSTA 
index at lag $i \Delta t$, and $\Delta t$ is in days. For the total number of lags $(K)$ we use 61 days. Though it could be argued a greater number of lags is necessary, autocorrelations of $\bar{Z}_{\chi(t)}$ at 30 days aside of the date approach zero over the midlatitude Pacific and North America. The statistically significant correlation coefficient $\left(r_{\text {sig }}\right)$ is then

$$
r_{\text {sig }}=\frac{X}{\sqrt{n-3}} .
$$

Here $X$ is the absolute value of the desired confidence interval on a normal distribution. To satisfy statistical significance at the $95 \%$ level, $X=1.96$.

To evaluate the relationship of Coop precipitation data to Pacific SSTs, we introduce regional time-evolving precipitation indices for the Great Plains and the Southwest. At an individual station, for each day a 30-day precipitation total is computed centered about the date. A missing 30-day total for the station is recorded if there are more than five missing days in the record. For each date the years are ordered highest to lowest according to the precipitation totals. The station precipitation total is considered above (below) average on that date if a given year ranks in the top (bottom) 20 years. The number of stations in the region $(S)$ recording an aboveaverage $\left(S_{\text {wet }}\right)$ or below-average $\left(S_{\text {dry }}\right)$ precipitation total are tallied for each date. The regional precipitation index is then

$$
\operatorname{PR}(t)=\frac{S_{\mathrm{wet}}(t)-S_{\mathrm{dry}}(t)}{S} .
$$

We correlated the precipitation indices with the three Pacific SST indices throughout the entire summer, using all the years of record.

Considering summer precipitation in such a way has several advantages. The use of point source precipitation, which is not normally distributed, is avoided. As with the average $Z$ score correlation analyses for reanalysis variables, we consider a time-evolving relationship between Pacific SSTs and precipitation. The actual station precipitation totals, typically the accumulation of small-scale thunderstorm events, are less important than whether it was generally wet or dry over the area in the 30-day period. The precipitation indices contain a large sampling of stations within each area, so any trends are likely to mirror those in MFC and reflect real large-scale climate variability.

\section{Correlation analyses for ENSO and North Pacific composites}

\section{a. Time series of Pacific SST indices}

The average summer Pacific SSTA indices for 195097 are shown in Fig. 2 and Table 2. We note, as in Mantua et al. (1997), that the NP and Niño-3 indices that compose the $\mathrm{P}$ index are not independent of each other. Niño-3 is most related to the NP index in spring and early summer, with an average correlation of 0.36
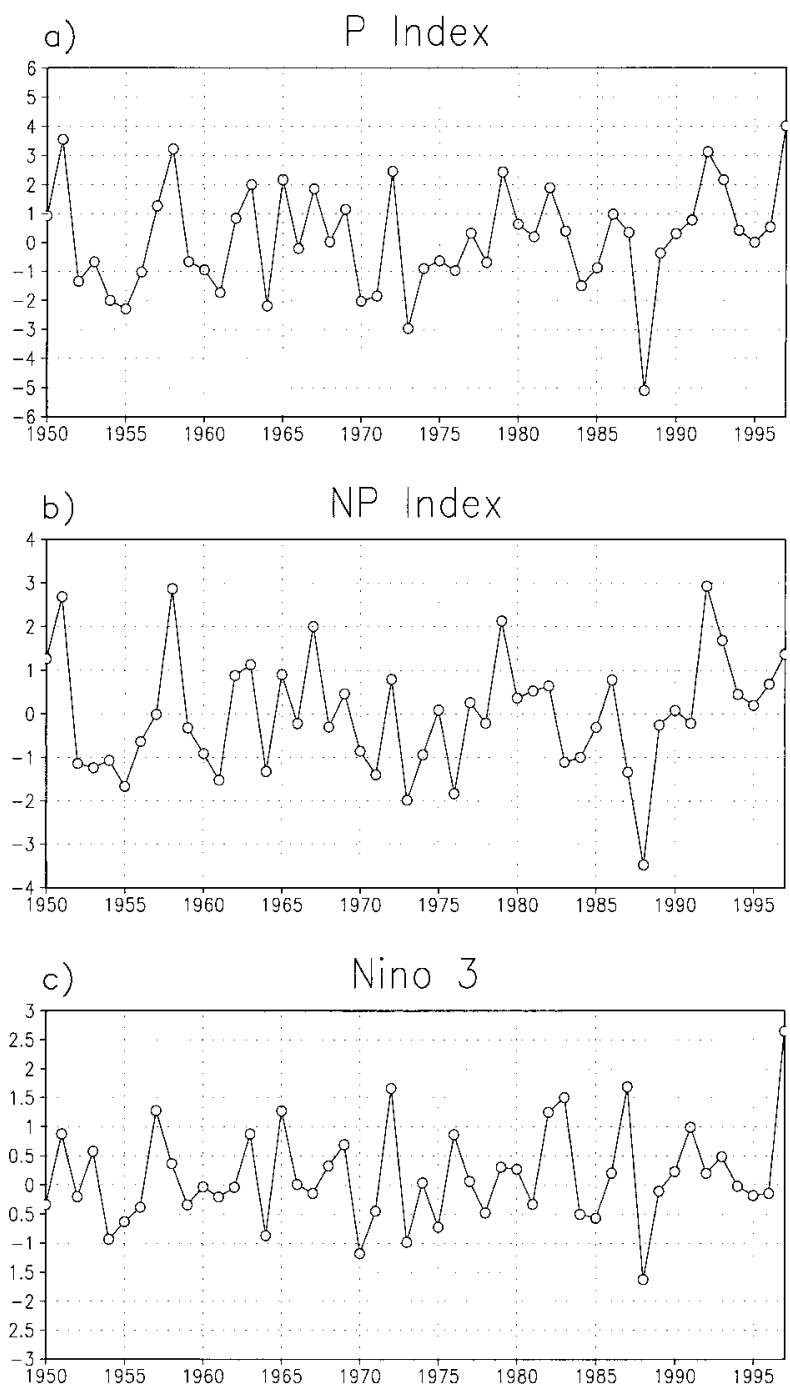

FIG. 2. Average Jun-Aug values of (a) P index, (b) NP index, and (c) Niño-3 index from 1950 to 1997.

in the period March through July. Near-zero values of the P index arise when Pacific SSTs are near average, or when strong tropical and North Pacific SSTs occur in destructive combinations, such as in 1976 and 1983. In the Great Plains, long-term variation in the P index seems to correspond with sustained dry (low P) or wet periods (high $\mathrm{P}$ ). Using the standardized precipitation index in Colorado, McKee et al. (1999) note the wet periods since 1950 as $1957-59,1965-75$, and 1979-96, and the dry periods as 1951-57, 1963-65, and 197578. An opposite relationship may exist in Arizona, which experienced wet summers in the mid-1950s coincident with frequent monsoon-related flash flood events (Carleton et al. 1990; Hirshboeck 1999). The following time-coincident correlation analyses for the ENSO and North Pacific composites are presented as 15-day snapshots starting at Julian day 140 (20 May) through Julian day 245 (2 September), respectively. 
Note that for the North Pacific composite, a higher value of correlation is required for statistical significance because of the smaller sample size.

\section{b. Upper-level circulation}

In the ENSO composite, there is a time evolution of correlation patterns between the Niño-3 index and $\bar{Z}_{\Phi_{500}(t)}$ (Fig. 3). A coherent series of atmospheric teleconnection patterns across the Pacific Ocean and North America occur during the course of the summer season. In late spring (days 140 and 155), the Niño-3 index is correlated with a positive phase of the North Pacific pattern, with height deviations in the western and central North Pacific $(r=-0.5)$ and over the Gulf of Alaska $(r=0.6)$. The positive (negative) phase of the North Pacific pattern, a preferred El Niño (La Niña) response during the spring, is associated with a southward (northward) shift of the jet stream across the North Pacific (Bell and Janowiak 1995). The spring storm track is directed toward southern California and the Southwest (Pacific Northwest). Though the positive (negative) phase of the North Pacific pattern in winter and spring brings above- (below-) average precipitation in the Southwest, it precedes dry (wet) monsoons (Higgins and Shi 2000).

The most statistically significant relationship between the Niño-3 index and upper-level circulation in the ENSO composite is at monsoon onset in late June and early July, not monsoon peak in late July and early August. At onset, Niño-3 is correlated with the negative phase of the Pacific transition (PT) pattern, which occurred in association with the flood of 1993 in the midwestern United States (Bell and Janowiak 1995). The PT pattern appears exclusively in summer and is distinct from the ENSO-associated winter teleconnection patterns. A stronger than average trough (Niño-3 high) or ridge (Niño-3 low) is centered in the northern Rocky Mountains. The strongest negative correlation with $\bar{Z}_{\Phi_{500}(t)}$ in North America $(r=-0.7$, day 185) during the entire summer, significant at the $99 \%$ level, is centered over Montana in late June to early July. Like with the winter Pacific North America pattern, PT is part of a coherent series of height deviations that extend across the Pacific with centers of action near $25^{\circ} \mathrm{N}, 150^{\circ} \mathrm{E}(r$ $=0.4)$, the central North Pacific $(r=-0.6)$, and the Gulf of Alaska $(r=0.3)$. In late July and August (day 200 onward) the correlation between Niño-3 and $\bar{Z}_{\Phi_{500}(t)}$ becomes statistically insignificant.

If the hypothesis offered by Gurshunov and Barnett (1998) is true for the summer as well as winter, we would expect statistically significant patterns in atmospheric circulation for the North Pacific composite (when ENSO is neutral). The correlation of the NP index with $\bar{Z}_{\Phi_{500}(t)}$ for the North Pacific composite (Fig. 4) reveals a different and coherent teleconnection pattern. Note that only days 155-200 are shown in Fig. 4. A significant relationship of the NP index to the negative phase of the east Pacific (EP) pattern emerges in June and July. On day 170, there are centers of action in the central North Pacific $(r=-0.6)$, the Gulf of Alaska $(r$ $=0.6$ ), and the northern Great Plains and upper Midwest $(r=-0.6)$. As with the relationship with Niño-3 and the PT pattern in the ENSO composite, the relationship of the NP index to the EP pattern becomes less statistically significant through late July and August (not shown). Tropical and North Pacific SSTs are related to the location of the monsoon ridge in distinct ways. A low (high) Niño-3 is related to a north (south) displacement of the monsoon ridge from its climatological position. A low (high) NP index is related to a northeast (southwest) displacement of the ridge.

The evolution of the these teleconnection patterns is linked to rapid changes in the mean climatological features associated with NAMS. Figure 5 shows the climatological evolution of the 200-mb zonal winds across the Pacific. A strong Pacific jet extending from Japan across the central Pacific is present from late May through the beginning of July. Winds in the core region of the jet range from 25 to $35 \mathrm{~m} \mathrm{~s}^{-1}$. As the monsoon ridge evolves over North America, the core of the Pacific jet retreats northward and dramatically weakens to nearly half its spring value $\left(15-20 \mathrm{~m} \mathrm{~s}^{-1}\right)$. The upper-level monsoon ridge over the western United States, as seen from the climatological evolution of 500-mb geopotential height, attains its maximum strength over the Four Corners region in late July and August (Fig. 6). Coincident with the weakening of the jet over the Pacific, the jet over North America strengthens $\left(25 \mathrm{~m} \mathrm{~s}^{-1}\right.$ on day 200). The evolution of the monsoon ridge over the western United States also coincides with the maximum westward extension of the Bermuda high into the southeast United States (not shown).

\section{c. Atmospheric moisture}

It can be argued that reliability of NCEP-NCAR reanalysis moisture fields is questionable, especially in light of the poorly resolved topography over the western United States and limited rawinsonde observations. Previous NAMS climatological studies have also shown there are substantial differences in moisture transport between the European Centre for Medium-Range Weather Forecasts and NCEP-NCAR reanalyses (Higgins et al. 1997b; Schmitz and Mullen 1996). In spite of these serious concerns, the MF and MFC correlation analyses are vital to the present investigation of NAMS interannual variability because they 1 ) verify conclusions of previous work, 2) fit into a consistent framework of the teleconnection patterns revealed by analysis of 500-mb geopotential height, and 3) show identical trends as precipitation data from actual Coop observing sites, as discussed in the next section. The results of the correlation analyses for the moisture fields is shown for day 185 only in Fig. 7, when the teleconnection relationships are most statistically significant. 

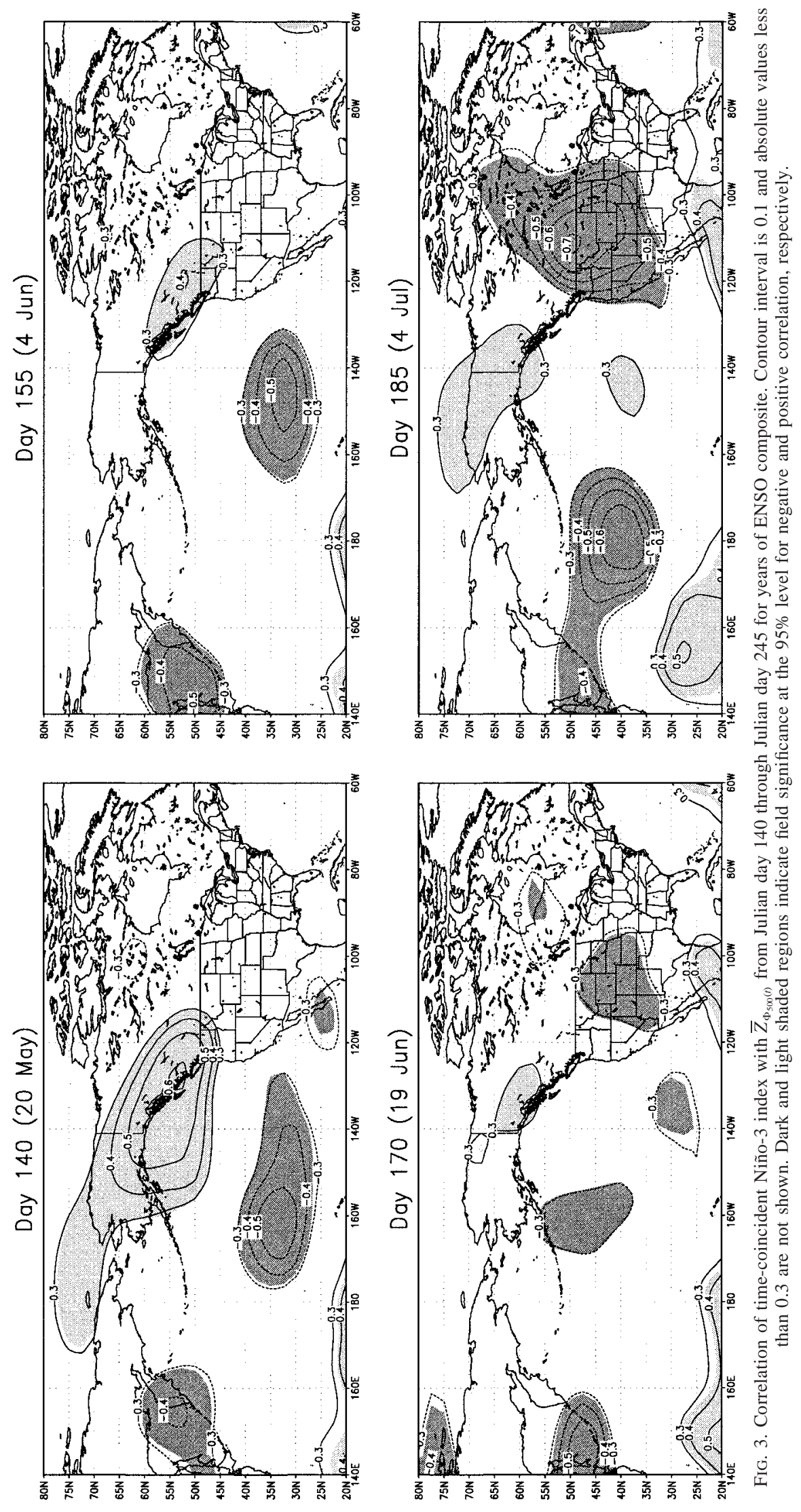

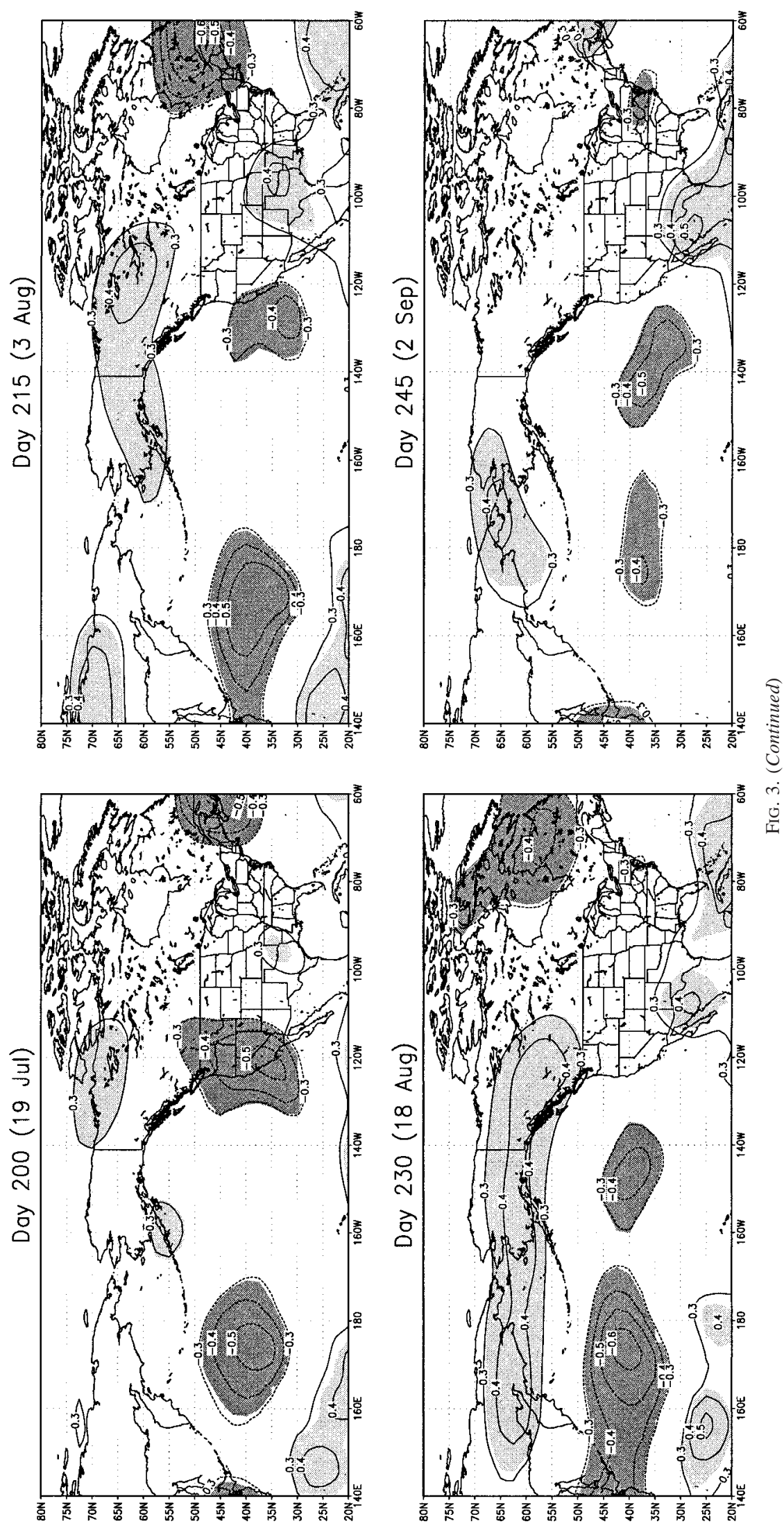

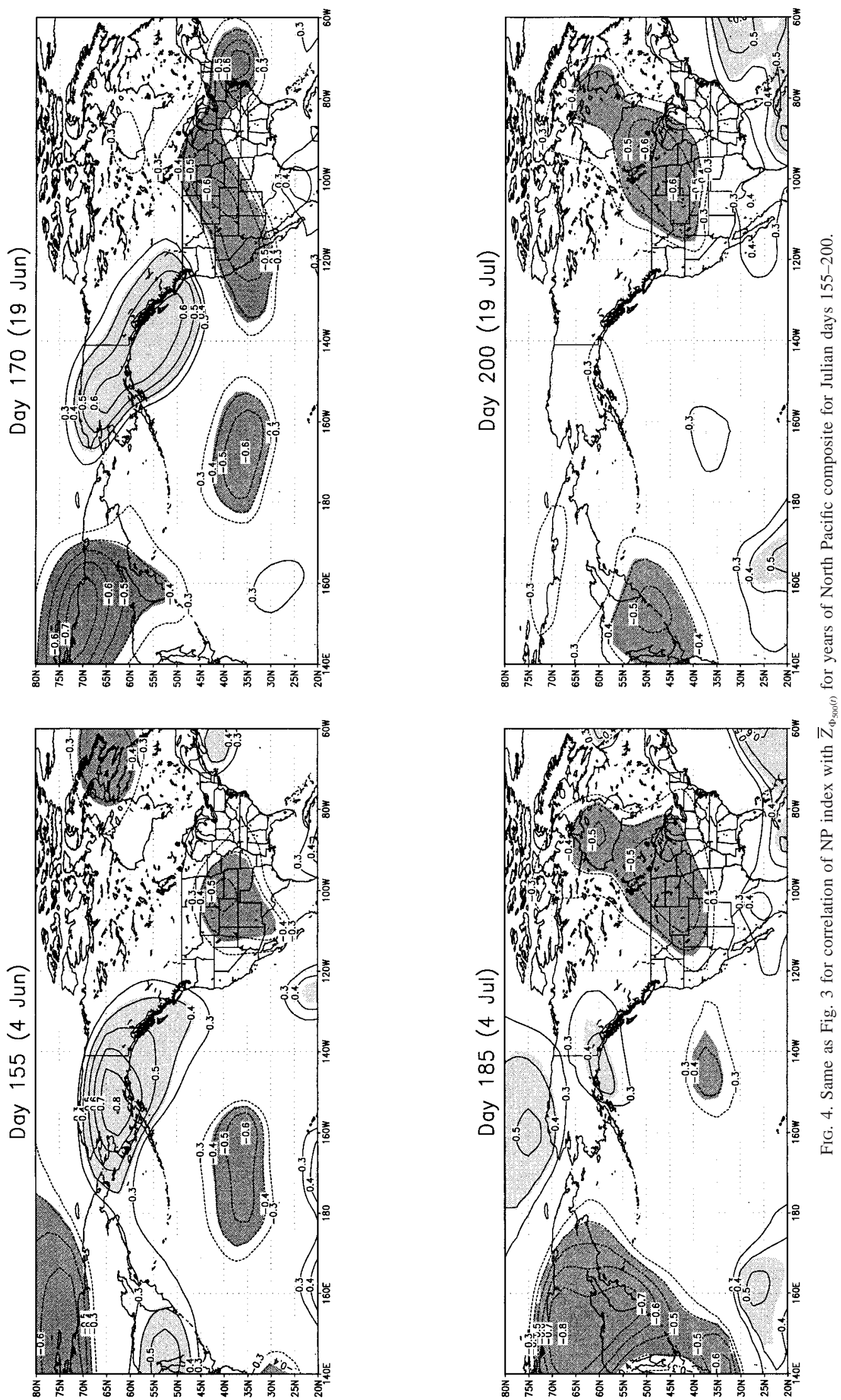

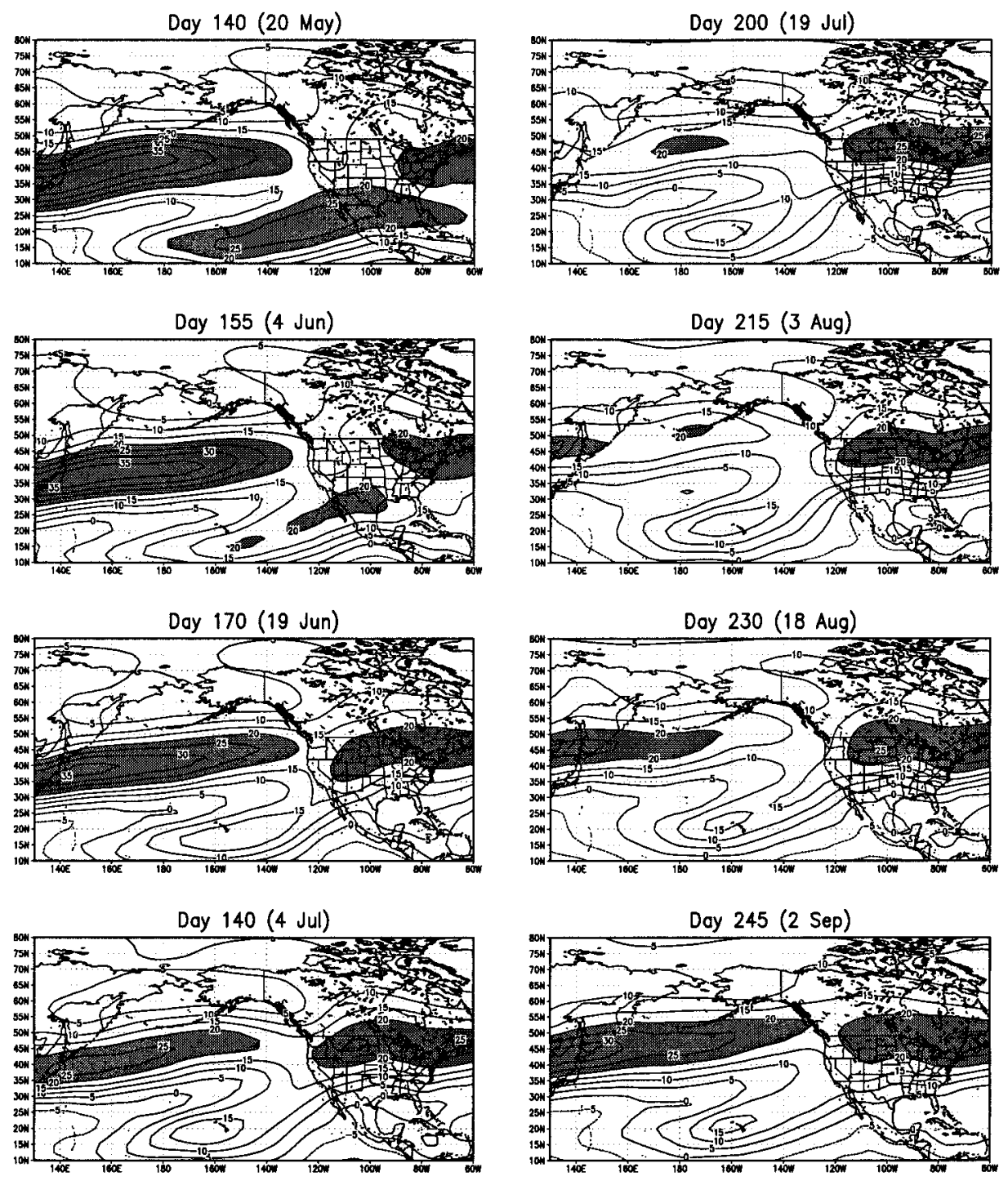

FIG. 5. Five-day running mean climatological evolution of 200-mb zonal wind over the Pacific and North America from Julian day 140 through Julian day 245. Contour interval is $5 \mathrm{~m} \mathrm{~s}^{-1}$. Values greater than $20 \mathrm{~m} \mathrm{~s}^{-1}$ are shaded.

The correlation of $\bar{Z}_{\mathrm{MF}(t)}$ with Niño-3 and the NP index for the ENSO and North Pacific composites is presented as a vector in Figs. 7a and 7b. There are two important features present in both of the composites that yield some additional information about the large-scale circulation associated with the teleconnection patterns. The circulation anomaly in either the northern Great Plains (ENSO composite) or the upper Midwest (North Pacific composite) indicates the presence of a surface ridge (La Niña, low NP) or trough (El Niño, high NP). The lowlevel circulation anomaly would modulate the strength of the Great Plains LLJ, directing low-level moisture into eastern Mexico or the central United States, respectively (Mo et al. 1997). Though not indicated in the analysis of $500-\mathrm{mb}$ geopotential height, the moisture flux correlation vectors in Figs. $7 \mathrm{a}$ and $7 \mathrm{~b}$ indicate a relationship to an anticyclonic (El Niño, high NP) or cyclonic (La Niña, low NP) circulation in the eastern Pacific west of Baja California (statistically significant in the ENSO composite). A cyclonic circulation in this area, associated with easterly waves or tropical cyclones, is a precursor to the Gulf surge, an episodic enhancement of the Baja LLJ and moisture transport into the Colorado River valley (Douglas and Real 2000). Carleton et al. (1990) also suggest the SST gradient between the Gulf of California and east Pacific would be larger in La Niña conditions, which would also strengthen the Gulf surge. The moisture flux analyses hint that the teleconnection patterns associated with tropical and North Pacific SSTs likely affect the lowlevel moisture transport of the Great Plains and Baja LLJs in the same way. A more detailed reanalysis over 

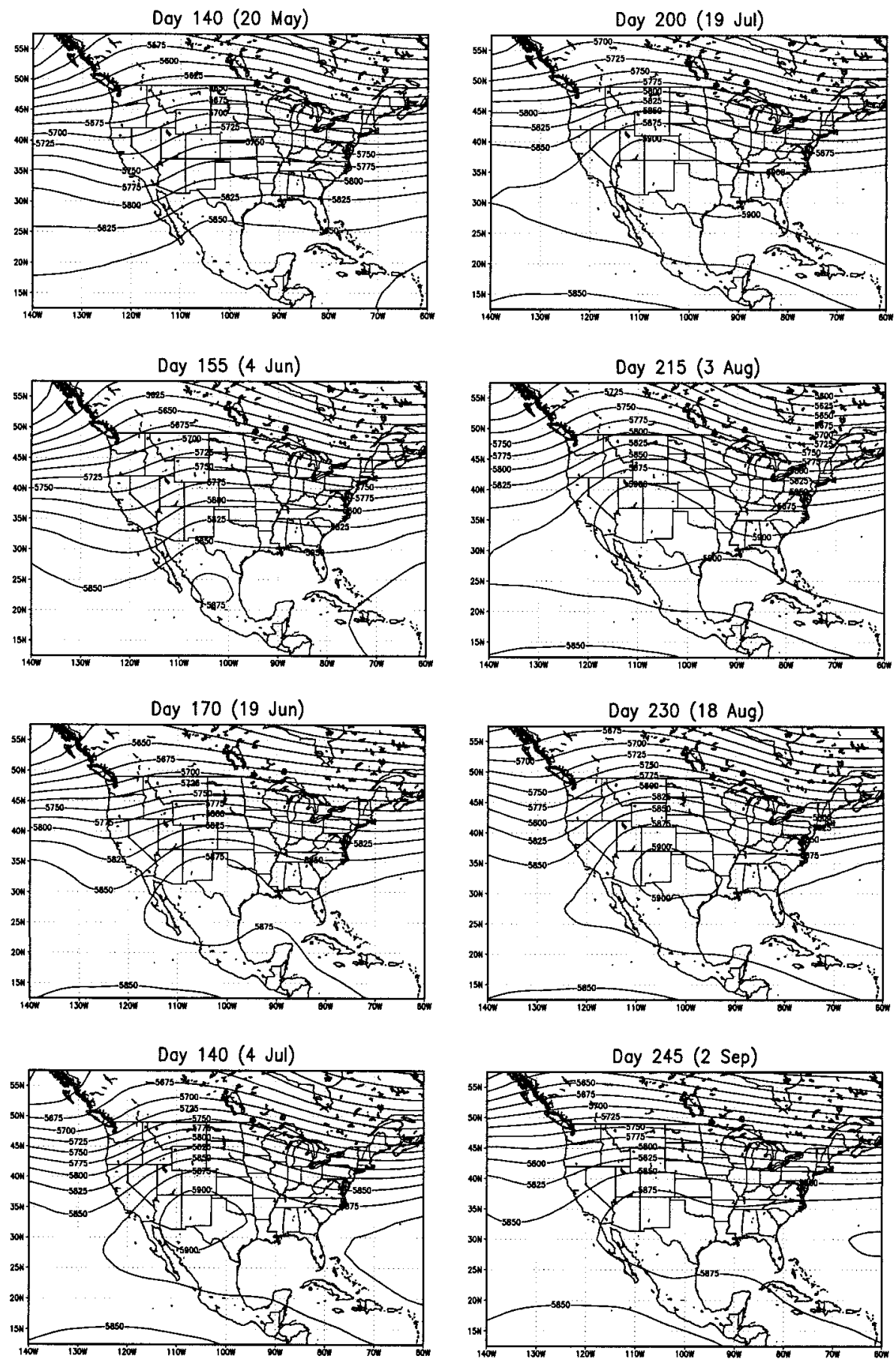

FIG. 6. Same as Fig. 5 for $500-\mathrm{mb}$ height over North America. Contour interval is $25 \mathrm{~m}$.

North America, long-term observational studies of both low-level jets, and associated regional atmospheric modeling are necessary to test these hypotheses.

Similarly, the correlation of $\bar{Z}_{\mathrm{MFC}(t)}$ with the SSTA indices for the composites is presented in Figs. 7c and $7 \mathrm{~d}$. Both composites show that an inverse relationship between atmospheric moisture in the Southwest and Great Plains exists interannually as well as seasonally.
In the ENSO composite, there is a statistically significant positive correlation of $\bar{Z}_{\mathrm{MFC}(t)}$ with Niño-3 $(r=0.7)$ in the northern Great Plains and the upper Midwest and a negative correlation near the northern end of the Gulf of California $(r=-0.7)$. In the North Pacific composite, the statistically significant positive correlation with $\bar{Z}_{\mathrm{MFC}(t)}$ is centered in the southern Great Plains $(r=0.7)$ and a negative correlation $(r=-0.5)$ exists over Ari- 


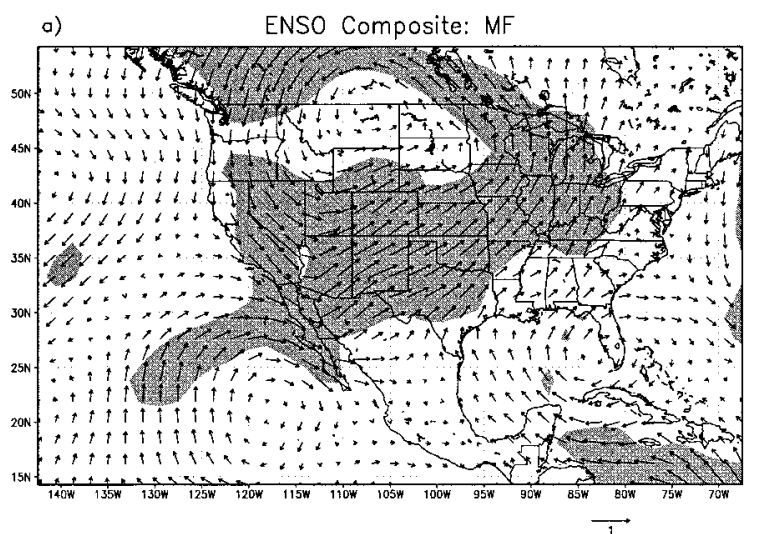

b) North Pacific composite: MF

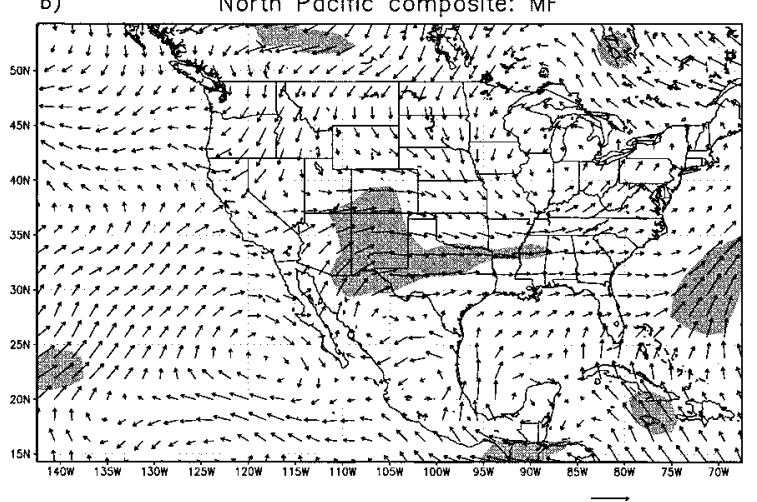

c) ENSO composite: MFC

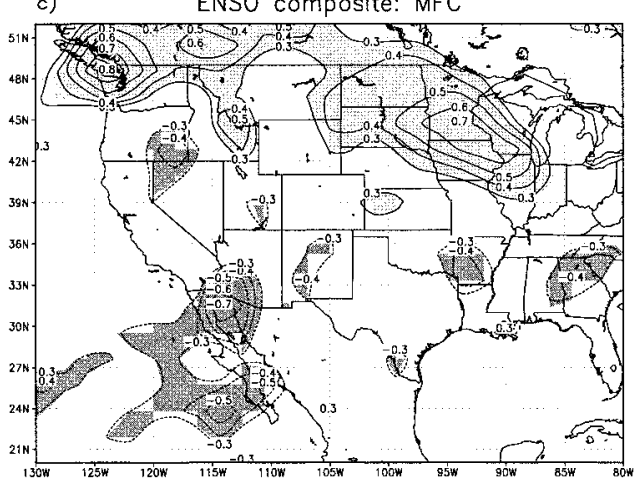

d) North Pacific composite: MFC

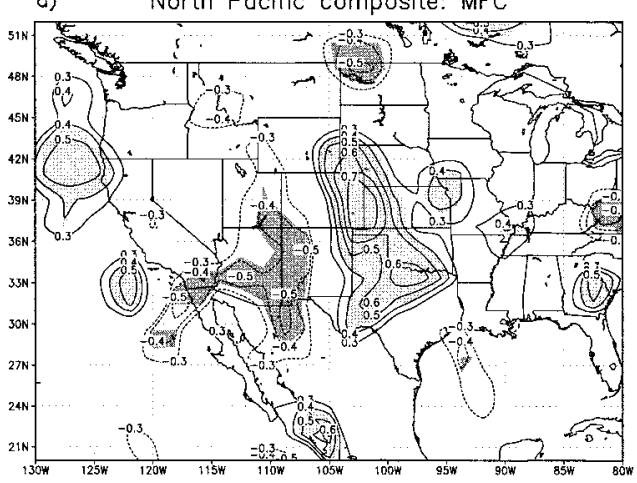

zona and New Mexico. When the PT and EP teleconnection patterns are strongest at monsoon onset, MFC is favored in either the Southwest or Great Plains and Midwest. The spatial relationship of tropical and North Pacific SSTs to Great Plains and Midwest MFC is in agreement with precipitation modes in the central U.S. precipitation found by Ting and Wang (1997), showing that the tropical and North Pacific associated teleconnection patterns have distinct relationships with atmospheric moisture and precipitation.

\section{Utility of the Pacific index}

Since tropical and North Pacific SSTs are related to different teleconnection patterns during NAMS evolution, the combined Pacific (P) index might be the better overall diagnostic measure for summer moisture across the western United States. To test this hypothesis, we ran the same correlation analyses as in section 4 using all the years available in the reanalysis and all three indices. The largest improvement in explained variance by the P index over Niño-3 and NP indices is for $\bar{Z}_{\mathrm{MF}(t)}$. Figure 8 shows, for example, the explained variance of $\bar{Z}_{\mathrm{MF}(t)}$ by the SST indices on day 185 . The $\mathrm{P}$ index explains the most variance of $\bar{Z}_{\mathrm{MF}(t)}$ over the Southwest (Fig. 8c), with increases in New Mexico by approximately $20 \%$ over the Niño-3 index and in northwest Mexico by approximately 5\%-10\% over the NP index.

The high and low $\mathrm{P}$ index composite summertime evolution of the dominant daily component of MFC was constructed (Fig. 9) using the 15 highest and lowest summer average $P$ index years shown in Fig. 9 and Table 2. These 15-yr averages are compared to the 50-yr MFC climatology in the same figure. The greatest differences in MFC between high and low $\mathrm{P}$ index years in the Great Plains and Southwest are at monsoon onset. Differences in MFC evolution in the Southwest begin in mid-June. If the onset of the monsoon is defined as the point where the average dominant daily component of MFC becomes positive in the Southwest, there is a difference of about 10 days in onset dates between high $\mathrm{P}$ (16 July) and low P (5-6 July) years in the Southwest. These dates are slightly later and earlier, respectively, than the climatological onset date of 7 July that Higgins et al. (1997b) obtained using area-averaged precipitation data for their Southwest region. Differences in Great Plains MFC become apparent by the beginning of June (Fig. 9b). MFC increases (decreases) in the Great Plains after this time in the high (low) $\mathrm{P}$ index years. The

$\leftarrow$

FIG. 7. Correlation of Niño-3 and the NP index with reanalysis moisture variables for years of ENSO and North Pacific Pacific composites, respectively. The correlation with $\bar{Z}_{\mathrm{MF}(t)}$ is shown in (a) and (b) with a unit vector length of 1 (see scale at bottom of figure). The correlation with $\bar{Z}_{\mathrm{MFC}(t)}$ is shown in (c) and (d). Contour interval is 0.1 and absolute values less than 0.3 are not shown. Shading indicates field significance at the $95 \%$ level. 

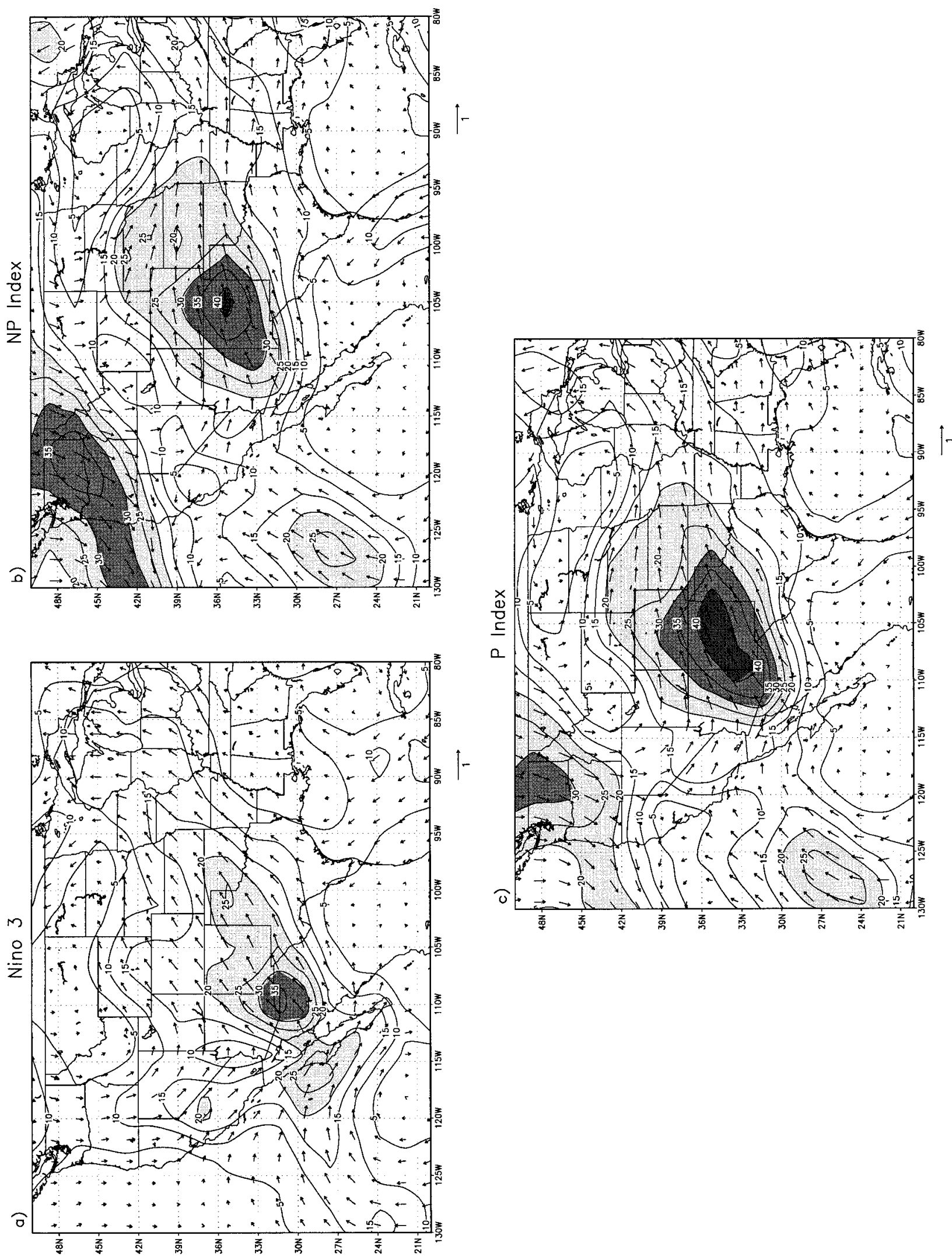
climatological decrease in MFC that occurs near the beginning of July (Fig. 9b) is delayed until early to midJuly in high $\mathrm{P}$ index years. The absolute percentage difference in MFC from climatology for high and low $\mathrm{P}$ index years is much higher in the Great Plains (50\%$100 \%)$ than in the Southwest $(5 \%-10 \%)$, where moisture is less variable, on average. The evolution of MFC abruptly reverts to climatology after the beginning of August, when the teleconnection patterns break down.

The behavior of the correlation of Great Plains and Southwest precipitation indices with the $\mathrm{P}$ index shows some difference from the correlation of the Niño-3 and NP indices with $\bar{Z}_{\mathrm{MFC}(t)}$, but results are broadly consistent (Fig. 10a). The greatest discrepancy is during May in the Southwest, when the precipitation index shows a strong positive correlation with the $\mathrm{P}$ index $(r>0.5)$. The positive relationship in spring likely reflects the influence of the North Pacific pattern on the winter and spring storm track into the southwest United States. However, as the PT and EP relationships emerge and the monsoon ridge becomes the dominant control on precipitation in mid-June the correlation between the Great Plains and Southwest begins to diverge. The maximum correlation with the $\mathrm{P}$ index occurs near monsoon onset, 29 June (day 180) in the Great Plains $(r=0.64)$ and 9 July (day 190) in the Southwest $(r=-0.37)$. Great Plains and Southwest precipitation are inversely related until the end of July. The maximum absolute values of $r$ in both regions is largest when the combined $\mathrm{P}$ index is used in the correlation analyses. Beyond late July the correlation with the P index in the Southwest is weakly positive but not statistically significant. A secondary maximum in correlation appears in the Great Plains in August that does not appear in MFC, possibly due to moisture recycling by local evaporation and transpiration. The precipitation indices, in general, capture the same time evolution of the NAMS relationship to Pacific SSTs revealed in MFC, particularly at monsoon onset. They confirm that a conclusive link exists between reanalysis MFC and point source station precipitation data considered over broad regions, at least in the United States.

Extending the analysis with the precipitation indices through the whole year (Fig. 10b) verifies the presence of established winter ENSO-NPO precipitation relationships in the western United States. In addition to summer, precipitation indices in the Great Plains and Southwest are significantly related to Pacific SSTs $(r>$ 0.3 ) in the same way during early spring (March) and mid- to late fall (November). These peaks reflect an intensified (weakened) storm track through the southwest United States in El Niño (La Niña) years. Though local convective thunderstorms or mesoscale convective complexes are the dominant mechanism for summer rainfall in the Southwest and the Great Plains, precipitation in the summer has an equally strong, if not stronger, relationship to Pacific SSTs as in winter.

Given this evolution in precipitation relationships with Pacific SSTs, one might pose the question of how a persistent ENSO-NPO regime would affect long-term dry or wet periods. In this context, "long term" refers to a period of approximately six months to several years. In the Southwest the sign of the correlation dramatically reverses between winter and summer. Dry or wet periods in the Southwest may be seasonally intense but weaken in the long term. In the Great Plains, however, the sign of correlation of precipitation with the $\mathrm{P}$ index is nearly always positive through the entire year. Persistent $\mathrm{Pa}-$ cific SSTs, therefore, would tend to amplify long-term wetness or dryness there. The mid-1950s drought and the extended wet period since the late 1970s are good examples (e.g., McKee et al. 1999).

\section{Time-lagged relationships with Pacific SSTA indices and SSTA evolution}

The simultaneous correlation analyses, using all the reanalysis years, were repeated with Pacific SST indices lagged from 1 to 4 months. Only the variable $\bar{Z}_{\Phi_{500}(t)}$ is considered for day 185, when the simultaneous relationships are strong. The correlation of Niño-3 with $\bar{Z}_{\Phi_{500}(t)}$ shows a relationship to atmospheric circulation that is strongest in the simultaneous correlation analyses and statistically significant at the $95 \%$ level up to a 4month lag (Fig. 11a). Though a strong relationship exists between the NP index and $\bar{Z}_{\Phi_{500}(t)}$ in the simultaneous correlation analyses, there is no statistically significant relationship at just a 2-month lag (not shown). Spring North Pacific SSTs in the regions used for the NP index have little relationship to subsequent summer atmospheric circulation anomalies. A similar result was obtained by Ting and Wang (1997) in a lag correlation of summer average 500-mb geopotential height with their North Pacific mode of SST related to summer precipitation variability in the central United States.

Higgins et al. (1999) showed that an association with tropical Pacific SSTs is important for the NAMS. Prior to wet monsoons, cold SST anomalies appear in the equatorial Pacific cold tongue near the date line in winter and increase in amplitude during the spring. These changes in tropical Pacific SST are associated with a weakened, northward displaced ITCZ and suppressed local Hadley circulation. The opposite is true for dry monsoons. The coherence of summer circulation anomalies with antecedent spring Niño-3 suggests tropical Pacific SSTs may be a good NAMS predictor, though

FIG. 8. Correlation and percent explained variance $\left(r^{2}\right)$ of $\bar{Z}_{\mathrm{MF}(t)}$ on Julian day 185 (4 Jul) by (a) Niño 3, (b) NP index, and (c) P index using all reanalysis years. Shading intervals at $20 \%, 30 \%$, and $40 \%$. Vector length is 1 and vector scale is shown at bottom of each panel. 

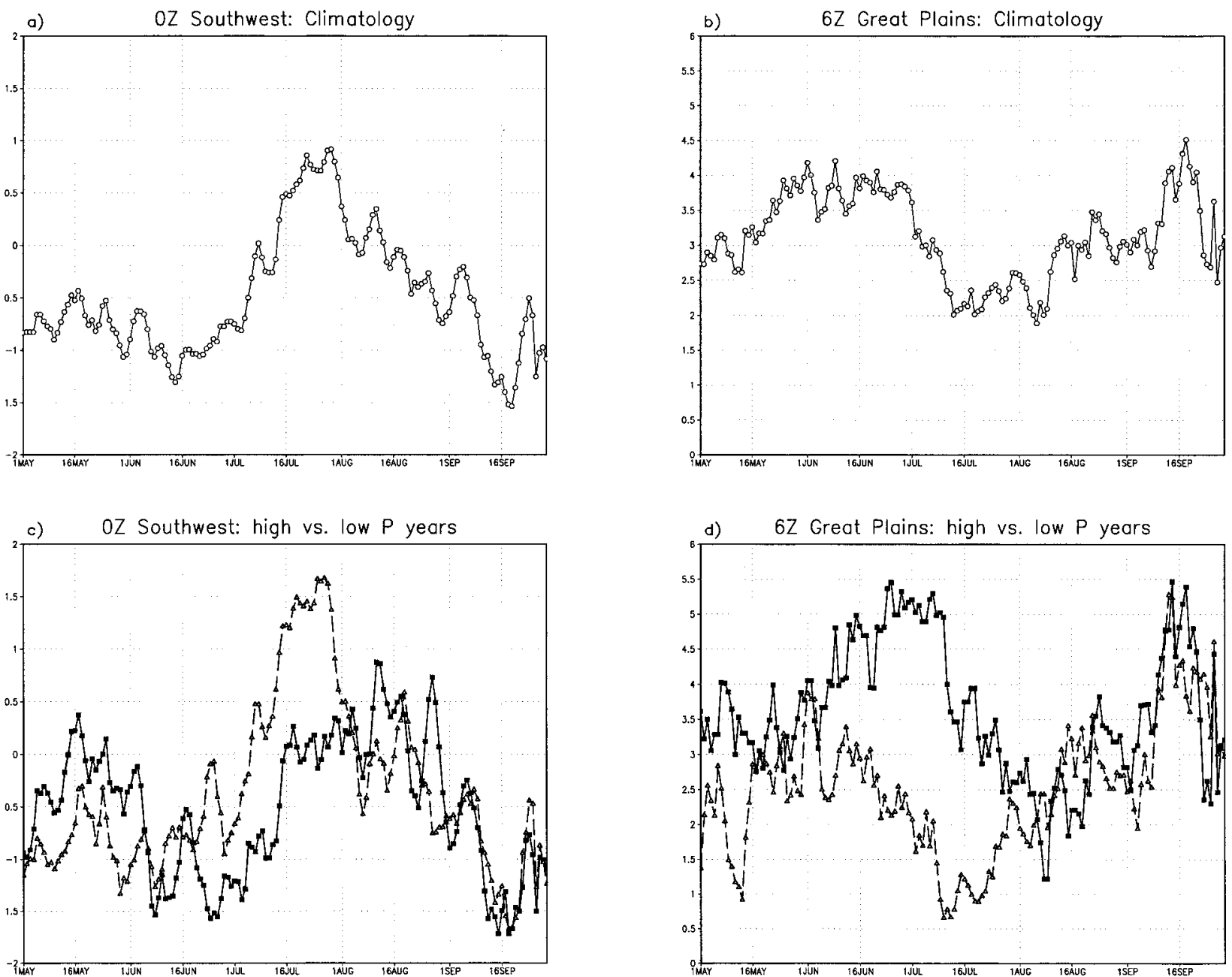

FIG. 9. Evolution of the dominant daily component of integrated moisture flux convergence (units: $\mathrm{mm} \mathrm{day}^{-1}$ ) for Southwest (0000 UTC) and Great Plains (0600 UTC) from May to Sep. The 50-yr reanalysis climatology is shown in (a) and (b). The 15 composite high P index (solid line with squares) vs low P index (dashed, line with triangles) summers are shown in (c) and (d).

the physical mechanisms relating the two need to be investigated.

The weak lag correlation using the NP index is likely an artifact of the regions used to define it. Other areas in the North Pacific, besides that used for the NP index, may be more related to the NAMS in the spring season. Since NAMS interannual variability is related to the occurrence of the North Pacific pattern, the regions of SST associated with this winter and spring teleconnection should have a relationship to subsequent summer conditions. Higgins and Shi (2000) demonstrated that early onset monsoons in the Southwest are associated with warm SSTs in the subtropical North Pacific (near $20^{\circ} \mathrm{N}, 170^{\circ} \mathrm{W}$ ) and cold SSTs in the midlatitude central North Pacific $\left(40^{\circ} \mathrm{N}, 180^{\circ}\right)$ during winter. This distribution of SSTs is consistent with a negative phase of the North Pacific pattern, with cold SSTs in the vicinity of large sensible and latent heat fluxes near the northward-displaced jet stream. Higgins and Shi also developed a winter North Pacific SST index, similar in prin- ciple to the NP index in this study, and demonstrated its usefulness in predicting the monsoon onset date.

To further investigate whether the summer Pacific SSTAs may be part of a pattern that evolves in time, we use the Reynolds and Smith (1994) data. We compute the composite monthly evolution of SSTA, starting in the previous winter, using the 15 highest and 15 lowest P index summers (Figs. 12 and 13). For brevity, note that the SSTA evolution in Figs. 12 and 13 is shown in 2-month averaged time blocks. We use the $\mathrm{P}$ index here because this index, as discussed earlier, explains the greatest amount of variance in NAMS atmospheric moisture and precipitation. Two important features are revealed that have implications for NAMS predictability. First, the magnitude of SSTAs in the eastern tropical Pacific increases in time from the previous winter, confirming the earlier analysis of Higgins et al. (1998) relating monsoon onset date to the development of El Niño or La Niña conditions in the spring. Second, the North Pacific SST dipole is clearly seen in the summer months, 

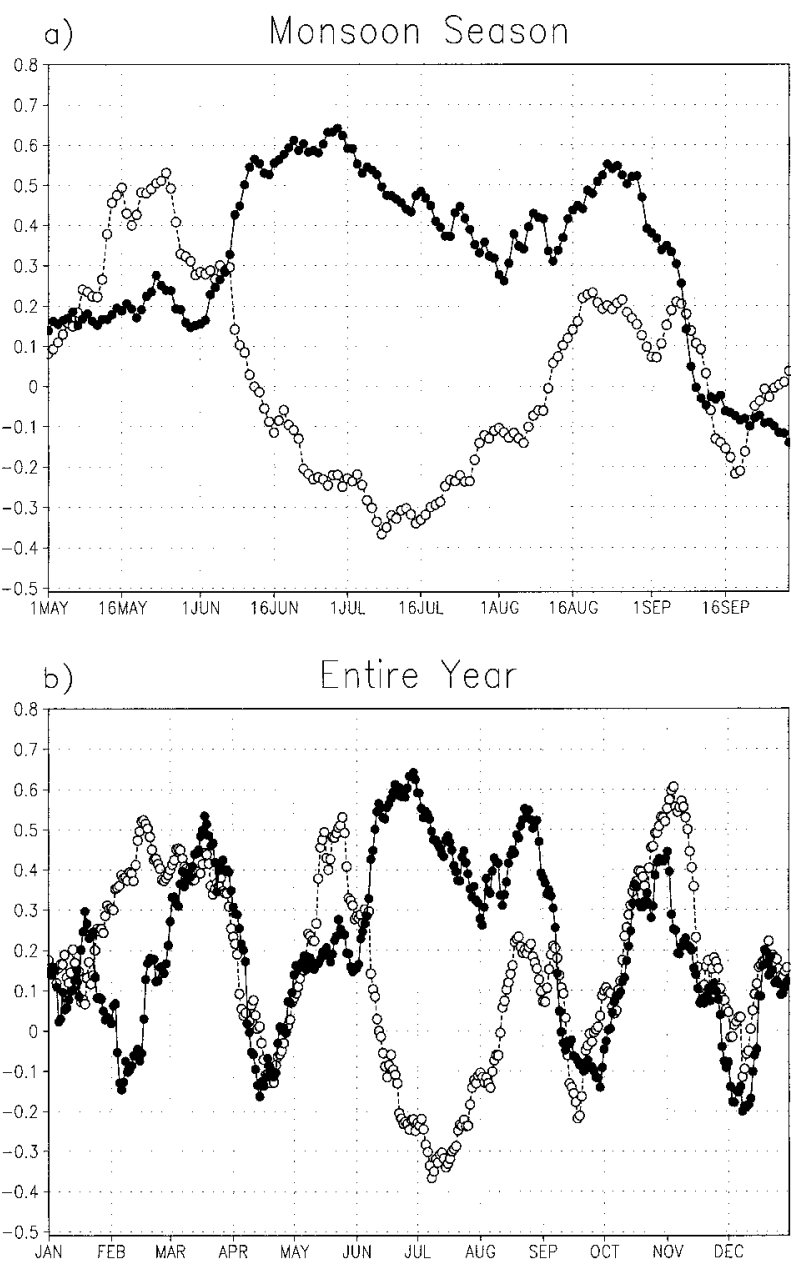

FIG. 10. Correlation of time-coincident $\mathrm{P}$ index with regional precipitation indices for the Great Plains (solid line, dark circles) and Southwest (dashed line, open circles) for (a) monsoon season (May through Sep) and (b) the entire year.

oriented along a diagonal from approximately $30^{\circ} \mathrm{N}$, $180^{\circ}$ to $50^{\circ} \mathrm{N}, 130^{\circ} \mathrm{W}$. Again, the location of the dipole in summer corresponds roughly to the North Pacific mode of Ting and Wing (1997). In the antecedent spring, the Pacific SST dipole is still present, but it is meridionally oriented along approximately $170^{\circ} \mathrm{W}$, corresponding with the North Pacific teleconnection pattern and consistent with Higgins and Shi (2000).

Using the COADS data, we constructed a modified NP index for the spring, shifting ENP box to $40^{\circ}-55^{\circ} \mathrm{N}$, $180^{\circ}-160^{\circ} \mathrm{W}$ (see Fig. 2) and repeated the lag correlation analysis in the same way described earlier. With the change in regions for the NP index in spring, a statistically significant relationship now exists between the atmospheric circulation and North Pacific SSTs at 4month lag (Fig. 11b). Using the modified NP index, we constructed a modified $\mathrm{P}$ index and repeated the lag correlation. The modified $\mathrm{P}$ index has the highest and most statistically significant correlation with $\bar{Z}_{\Phi_{500}(t)}$ at 4-month lag (Fig. 11c). The entire state of the tropical and extratropical Pacific in spring must be considered to maximize predictability for subsequent summer weather conditions in the western United States.

\section{Discussion}

The contrasting summers of 1993 and 1988 serve as archetypal climatologies associated with high and low P index, respectively. In the Midwest flood of 1993, a strong trough situated over the northern Rocky Mountains and northern Great Plains maintained westerly flow across all of the western United States in the summer. The jet stream and associated synoptic eddies were stronger than average and south of their mean climatological position. The Great Plains and Midwest, to the east of the trough and north of the jet stream, were favored for the development of thunderstorms in the form of mesoscale convective complexes (Bell and Janowiak 1995; Mo et al. 1997; Trenberth and Guillemot 1996). Monsoon rainfall in the Southwest was below average because onset was delayed until early August, the latest on record since 1948 (Okabe 1995; Higgins and Shi 2000). By contrast, in the drought of 1988, a monsoon ridge located over the Great Plains steered the jet stream north into Canada from late spring into early summer (Bell and Janowiak 1995; Trenberth 1992). The Great Plains and Midwest, on the subsiding branch of the ridge, received little precipitation and temperatures were much above average. There was enhanced easterly flow on the southern side of the ridge. The monsoon began early in late June and summer rainfall was above average in the Southwest (Higgins and Shi 2000). Though this circulation pattern broke down in mid-July and rainfall returned to normal in the central United States, the late summer rains were insufficient to break the hydrologic drought (Trenberth and Guillemot 1996).

Modeling studies of 1988 and 1993 suggest the distribution of tropical and midlatitude Pacific SSTs, and associated diabatic heating patterns, produced time-coincident teleconnection responses. Trenberth and Branstator (1992) argued that latitudinal variation in the ITCZ changed the distribution of tropical Pacific heating, in agreement with observations of dry and wet monsoon years (e.g., Higgins et al. 1998). Using a linearized baroclinic model, they showed that these heating patterns provide the sources and sinks for quasi-stationary Rossby waves that propagate into the extratropics. Liu et al. (1998) took a similar modeling approach with a stationary wave model linearized about the mean summer climate. However, they found that the summertime circulation pattern over North America was relatively insensitive to diabatic heating in the tropical Pacific. The greater effect on the circulation over North America was from diabatic heating associated with an upper-level trough or ridge off the west coast of the continent, diabatic heating in the western Pacific, and vorticity forcing by transient eddies.

Newman and Sardeshmukh (1998) demonstrated that 

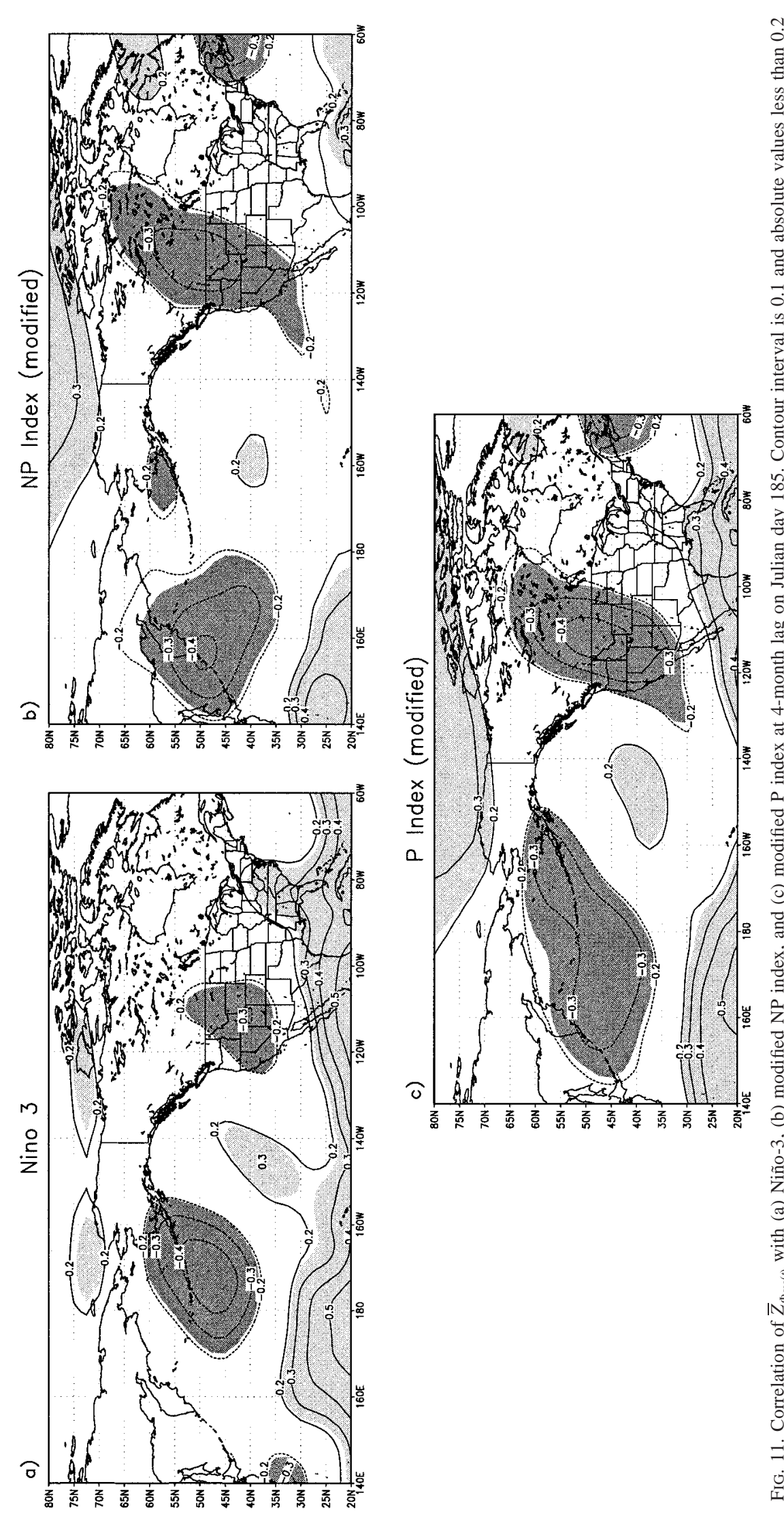

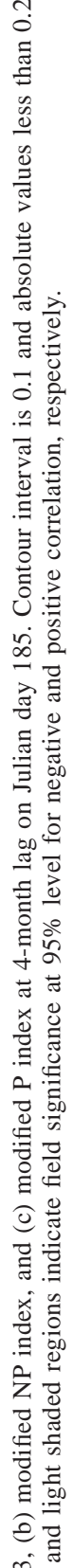

完

要

త 

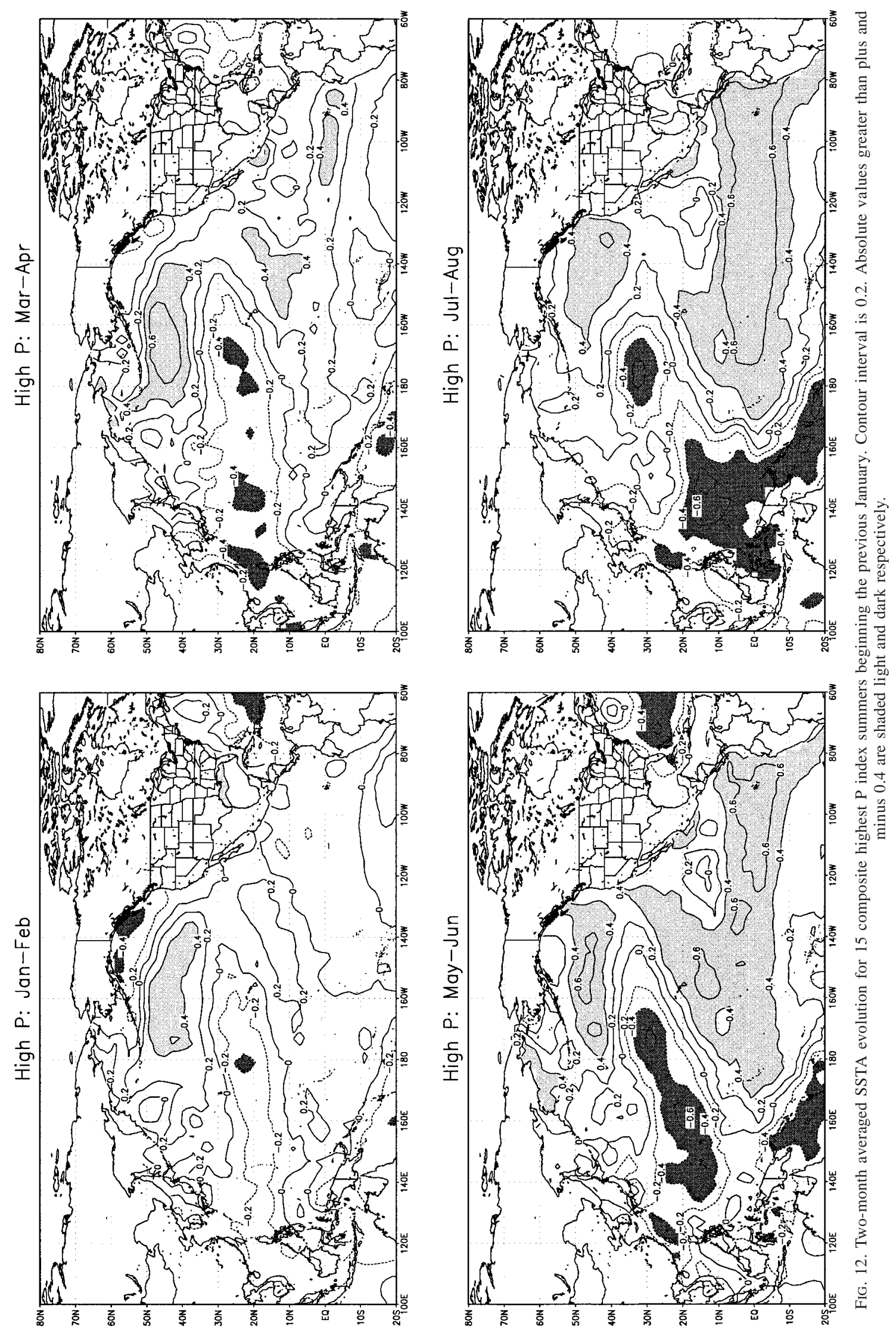

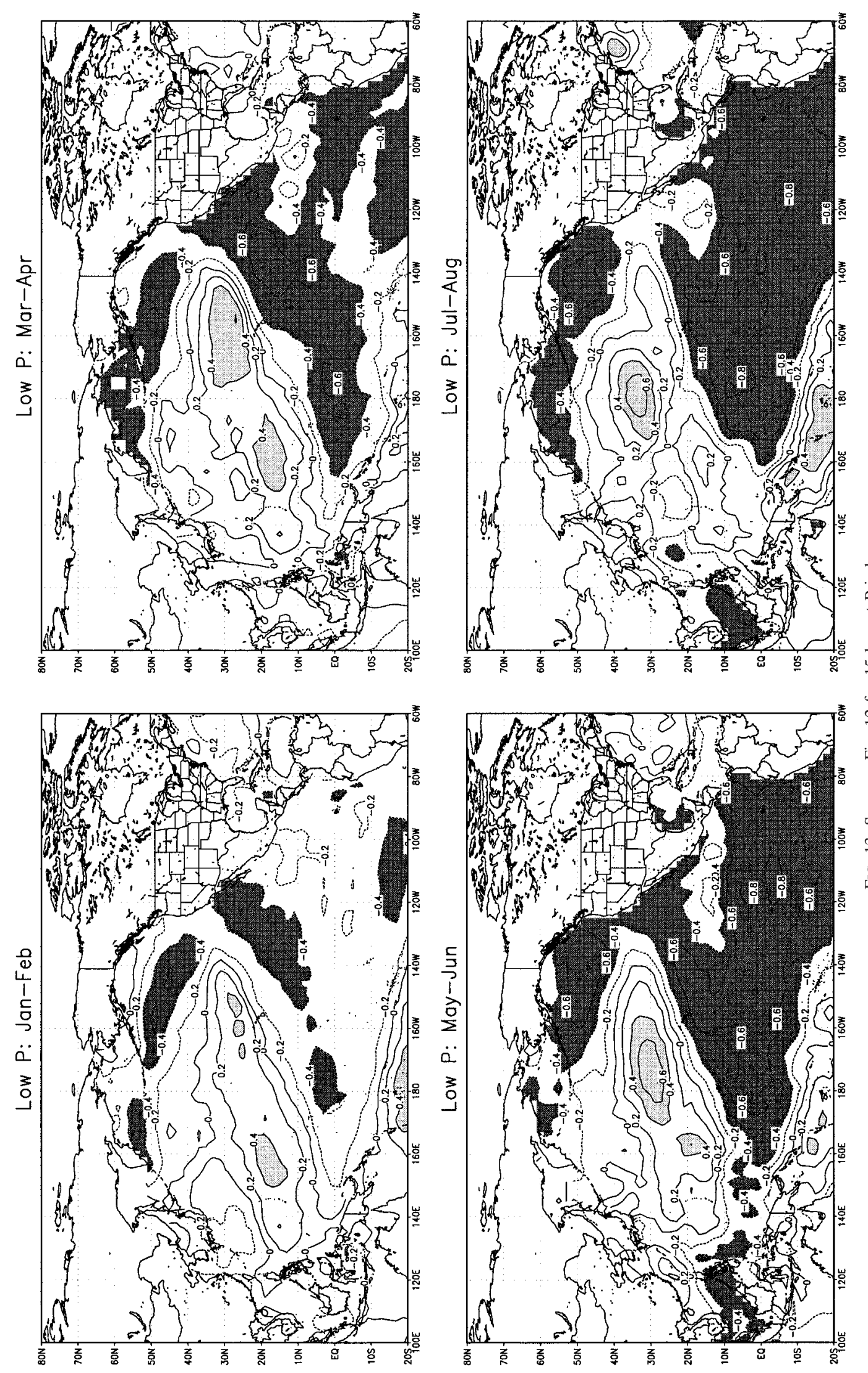

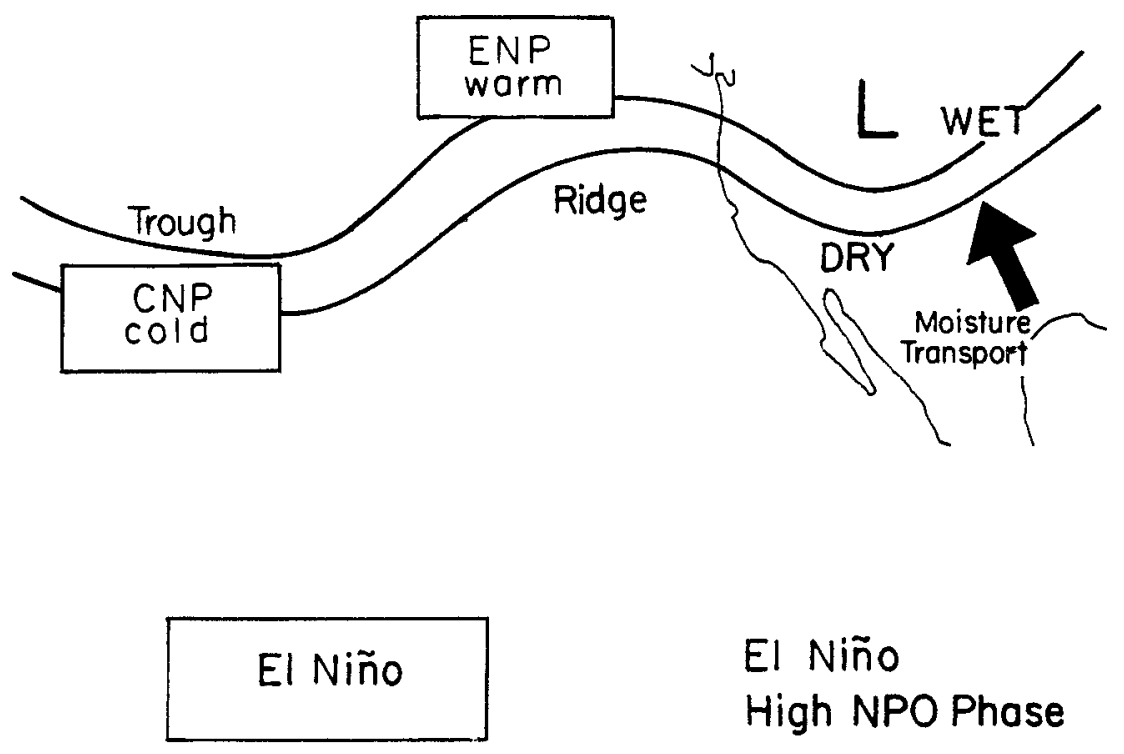

\section{El Niño \\ High NPO Phase}
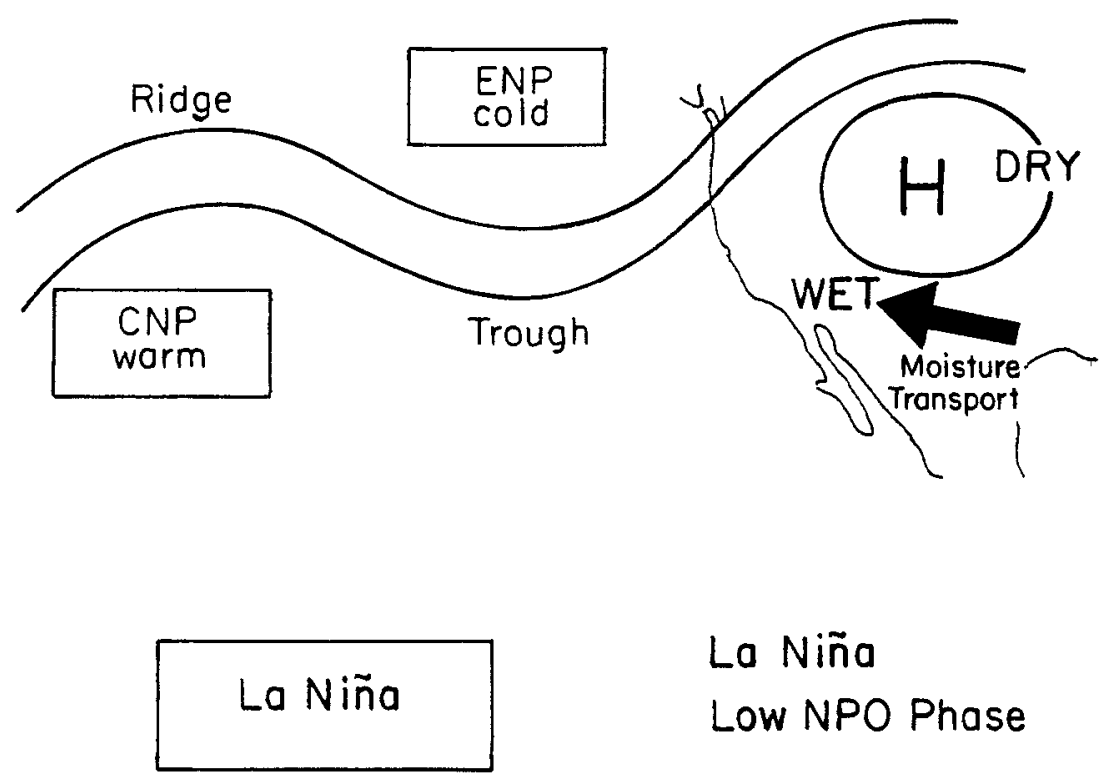

\section{La Niña \\ Low NPO Phase}

FIG. 14. Idealized relationship of monsoon ridge position and midlevel moisture transport to Pacific SSTs at monsoon onset.

height anomalies over western North America have a time-varying sensitivity to Rossby wave forcing in the Pacific. As the westerlies weaken, the forcing region shifts from the east and central Pacific in winter to the west Pacific in spring. Height anomalies over North America are most sensitive to forcing in the west Pacific in late spring as the Asian monsoon is intensifying, but this sensitivity diminishes in July and August. Chen and Newman (1998) also concluded that Rossby wave forcing from southeast Asia and the west Pacific were critical to the development of an anticyclone over central North America in the drought of 1988.
The spatial and temporal evolution of the teleconnection patterns in the present study is consistent with Newman and Sardeshmukh (1998). Tropical and North Pacific SSTs are each associated with distinct summer circulation responses over North America in the form of the PT and EP teleconnection patterns. The PT pattern (Fig. 3) appears to be related to forcing in the tropical Pacific that moves westward and northward with time from late spring to early summer. The EP pattern (Fig. 4) may also be related to forcing in the west Pacific or, more likely, off the west coast of North America as Liu et al. (1998) suggest in their modeling study. 
The PT and EP patterns have their maximum relationship to their respective Pacific SSTA indices at the monsoon onset. The weakening of the teleconnection patterns in mid- to late summer coincides with weakening of the Pacific jet, strengthening of the monsoon ridge, and the westward extension of the Bermuda high. These events always occur because their physical mechanisms are independent of Pacific SSTs. The Pacific jet weakens because baroclinicity in the Northern Hemisphere is weakest in mid-summer. The monsoon ridge over Mexico and the western United States evolves as a result of sensible heating from elevated heat sources and latent heating from diurnal thunderstorms (e.g., Barlow et al. 1998). Pacific SSTs appear to play a role in modulating the timing of these events in a climatological transition period in early summer. In short, teleconnections originating in the Pacific likely affect how the NAMS begins, but now how it ends.

Some modeling studies suggest that the North Pacific SST dipole develops as a result of time-coincident forcing by ENSO-related tropical convection (e.g., Alexander 1992; Lau and Nath 1996; Deser and Timlin 1997). These studies would suggest that North Pacific SSTs provide little predictive value beyond a synoptic timescale of several weeks. However, the presence of a statistically significant circulation relationship in the North Pacific composite suggests that the North Pacific affects the summertime circulation over North America, independent of ENSO. Moreover, the evolution of the NAMS is related to a seasonally evolving pattern of Pacific SSTAs. Accounting for the evolution of the North Pacific SST dipole and the development of ENSO conditions, the relationships between Pacific SSTAs and summer atmospheric circulation over North America are persistent from the antecedent spring. The entire time-evolving state of the Pacific, as expressed in the $\mathrm{P}$ index, should be considered in either the timecoincident or time-lagged relationships to maximize the explained variance of atmospheric circulation, atmospheric moisture, and regional precipitation. Future work should aim to further understand the physical mechanisms behind the seasonal cycle of interannual Pacific SSTA variability and its implications for NAMS predictability.

Modeling studies confirm that land surface conditions, which have not been investigated here, may also affect the development of monsoons (e.g., Anthes and Kuo 1986; Dirmeyer 1994; Meehl 1994; Sud et al. 1995). Gutzler and Preston (1997) have suggested that snow cover affects the surface energy budget of the Rocky Mountains and Colorado plateau in late spring, and, hence, the evolution of the monsoon ridge. In agreement with this hypothesis, Higgins et al. (1998) noted that wet (dry) monsoons in Arizona-New Mexico tend to follow winters with wet (dry) conditions in the Pacific Northwest and dry (wet) conditions in the Southwest. We suspect, however, that Pacific SST forcing is the dominant factor in the winter and summer climate of the southwest United States. The relationship between snowfall and NAMS precipitation is likely observed as a coincidence of the changes in large-scale teleconnection patterns associated with ENSO-NPO and precipitation in the Southwest between winter and summer.

Central and southern Mexico are not the focus of this study, but this area deserves mention because NAMS precipitation is most pronounced there. Statistically significant relationships have been found to exist between summer precipitation and tropical Pacific SSTs in this region (Higgins et al. 1999). In both ENSO and North Pacific composites, there are slight negative relationships between $\bar{Z}_{\mathrm{MFC}(t)}$ and Niño-3 and NP indices. However, these relationships are not as statistically significant nor as persistent as the relationships in the southwest United States or Great Plains. Long-term reanalysis atmospheric moisture may be worse over Mexico because of the paucity of continuous rawinsonde records. The interannual variability of the NAM in Mexico is probably less sensitive to the midlatitude teleconnection patterns associated with remote Pacific SSTs. Summer precipitation in Mexico is more likely tied to SSTs in the adjacent east Pacific, which in turn vary with ENSO. Colder (warmer) SSTs along the western Mexican coast would enhance (diminish) the ocean-land temperature gradient, hence the strength of the monsoon (Higgins et al. 1999). The effect of east Pacific tropical systems and their relationship to ENSO should also be considered (Reyes and Mejía-Trejo 1991; Douglas 2000). Mexican rainfall may also be influenced by factors independent of Pacific SSTs, such as the quasi-biennial oscillation (Douglas 2000). Because of the difference in climatological evolution and possible difference of controls on interannual variability, the NAMS in Mexico should be treated separately from the NAMS in the United States.

If the evolution of the NAMS in the United States is primarily driven by remote Pacific SST forcing in the early part of the monsoon, what happens during premonsoon and late monsoon periods? We speculate that at these times the land surface factors may become more important for the large-scale circulation. In 1988 and 1993, antecedent soil moisture influenced surface latent and sensible heat fluxes, which may have provided positive or negative feedback, respectively, to the drought or flood conditions (Giorgi et al. 1996; Trenberth and Guillemot 1996). Future investigation of the NAMS should explore the physical linkages between remote Pacific SST forcing, land surface processes, and NAMS evolution. Regional atmospheric models are well suited to such a task.

The fact that ENSO-NPO relationships with precipitation in the Southwest dramatically change through the seasons is a complicating factor in forecasting longterm drought or wet conditions in that region. Extended wetness and dryness in the Great Plains is very sensitive to variability in Pacific SSTs since ENSO-NPO is re- 
lated to precipitation in the same way throughout the year. The record or historically wet and dry periods in Colorado found by McKee et al. (1999) support this conclusion. The weather conditions in early summer must be a critical factor in determining the annual soil moisture surplus or deficit. Though there have been very dry summers like 1988 or 1983, the Great Plains have not experienced a long-term multiyear drought in the past two decades, corresponding with a period of sustained El Niño-high NPO conditions. The Great Plains could expect a greater frequency of long-term drought should these conditions change in the future.

\section{Summary}

In this study, a NAMS reanalysis climatology of 500$\mathrm{mb}$ geopotential height, integrated moisture flux, and integrated moisture flux convergence was computed using the 50-yr NCEP-NCAR daily reanalysis. A timevarying correlation approach was used to relate daily deviations from the climatology to three Pacific SSTA indices that capture the variability of tropical and North Pacific SSTs related to ENSO and NPO. New timeevolving precipitation indices, of Southwest and Great Plains stations, were also related to these Pacific SSTA indices.

Tropical and North Pacific SSTs are related to the occurrence of both Pacific Transition and East Pacific teleconnection patterns, respectively, over North America in summer. High (low) P index years are characterized by the negative (positive) phases of these patterns. A trough (ridge) is located over the northern Rocky Mountains and central Great Plains. These relationships are strongest at monsoon onset in late June and early July, when the teleconnection patterns control the largescale distribution of moisture across the western United States (Fig. 14). In the Great Plains, because the spring wet season is lengthened (shortened), early summer MFC and rainfall are above (below) average. In the Southwest, monsoon onset is late (early), and early summer MFC and rainfall are below (above) average. The Great Plains and Baja LLJs are likely related to Pacific SSTs, respectively, by the presence of a surface ridge or trough in the central United States and changes in tropical easterly wave activity. These relationships decay in the later part of the monsoon coincident with weakening of the jet stream across the Pacific and strengthening of the monsoon ridge over North America. These events always occur because their physical mechanisms are independent of Pacific SSTs.

Because tropical and North Pacific SSTs are associated with distinct teleconnection patterns, they are related to the deviation of the monsoon ridge from its climatological average position in different ways. Tropical Pacific SSTs are related to the variation in ridge position to the north and south, and North Pacific SSTs to variation in ridge position to the northeast and southwest. These ridge configuration are consistent with those of Carleton et al. (1990) associated with interannual variability of NAMS precipitation in the Southwest. The most coherent summer climate patterns over the entire western United States occur when Pacific SSTs are in a substantially high or low P index configuration, indicating that there is a constructive interference of ENSO and NPO in the summer as well as winter. The $\mathrm{P}$ index is the better diagnostic for summer climate in the western United States and the better predictor when the seasonally evolving state of Pacific SSTAs is considered.

Acknowledgments. This research was funded by the Significant Opportunities in Atmospheric Research and Science Program (SOARS) through the University Corporation for Atmospheric Research and the National Science Foundation, the Cooperative Institute for Research in the Atmosphere through NOAA, and NASA Grant NAG8-1511. The authors would like to acknowledge the comments from two anonymous reviewers that improved the manuscript.

\section{REFERENCES}

Adams, D. K., and A. C. Comrie, 1997: The North American monsoon. Bull. Amer. Meteor. Soc., 78, 2197-2213.

Alexander, M. A., 1992: Midlatitude atmosphere-ocean interaction during El Niño. Part I: The North Pacific Ocean. J. Climate, 5, 944-958.

Anthes, R. A., and Y. H. Kuo, 1986: The influence of soil moisture on circulations over North America on short time scales. Namias Symposium, Scripps Institution of Oceanography Reference Series, Vol. 86-17, J. O. Roads, Ed., 132-147.

Barlow, M., S. Nigam, and E. H. Berbery, 1998: Evolution of the North American monsoon system. J. Climate, 11, 2238-2257.

_ __ , and —_, 2000: ENSO, Pacific decadal variability, and U.S. summertime precipitation, drought, and streamflow. J. Climate, 14, 2105-2128.

Bell, G. D., and J. E. Janowiak, 1995: Atmospheric circulation associated with the Midwest floods of 1993. Bull. Amer. Meteor. Soc., 76, 681-695.

Bonner, W. D., 1968: Climatology of the low level jet. Mon. Wea. Rev., 96, 833-850.

Brenner, I. S., 1974: A surge of maritime tropical air-Gulf of California to the southwestern United States. Mon. Wea. Rev., 102, 375-389.

Bryson, R. A., and W. P. Lowry, 1955: The synoptic climatology of the Arizona summer precipitation singularity. Bull. Amer. Meteor. Soc., 36, 329-339.

Bunkers, M. J., J. R. Miller, and A. T. DeGaetano, 1996: An examination of El Niño-La Niña related precipitation anomalies across the northern plains. J. Climate, 9, 147-160.

Carleton, A. M., D. A. Carpenter, and P. J. Weser, 1990: Mechanisms of interannual variability of the southwest United States summer rainfall maximum. J. Climate, 3, 999-1015.

Castro, C. L., T. B. McKee, and R. A. Pielke Sr., 2000: The relationship of the North American monsoon to tropical and North Pacific sea surface temperatures as revealed by observational analyses. Climatology Rep. 00-1, Department of Atmospheric Science, Colorado State University, $95 \mathrm{pp}$.

Chen, P., and M. Newman, 1998: Rossby wave propagation and rapid development of upper level anomalous anticyclones during the 1988 U.S. drought. J. Climate, 11, 2491-2504.

Comrie, A. C., and E. C. Glenn, 1998: Principal components-based regionalization of precipitation regimes across the southwest 
United States and northern Mexico, with an application to monsoon precipitation variability. Climate Res., 10, 201-215.

Cowie, J. R., and T. B. McKee, 1986: Colorado precipitation event and variability analysis. Climatology Rep. 86-3, Department of Atmospheric Science, Colorado State University, 102 pp.

Deser, C., and M. S. Timlin, 1997: Atmosphere-ocean interaction on weekly timescales in the North Atlantic and Pacific. J. Climate, 10, 393-408.

Dirmeyer, P. A., 1994: Vegetation stress as a feedback mechanism in midlatitude drought. J. Climate, 7, 1463-1487.

Douglas, A., 2000: The influence of eastern North Pacific storms on summer rainfall in Mexico. Second Southwest Weather Symp., Tucson, AZ.

Douglas, M. W., 1995: The summertime low-level jet over the Gulf of California. Mon. Wea. Rev., 123, 2334-2347.

_ of moisture fluxes over the Gulf of California and surrounding regions during the summer. Postprints, Second Southwest Weather Symp., Tucson, AZ National Weather Service, The University of Arizona, and COMET.

_ R. A. Maddox, K. Howard, and S. Reyes, 1993: The Mexican monsoon. J. Climate, 6, 1665-1677.

Giorgi, F., L. O. Mearns, C. Shields, and L. Mayer, 1996: A regional model study of the importance of local versus remote controls of the 1988 drought and 1993 flood over the central United States. J. Climate, 9, 1150-1162.

Gurshunov, A., and T. B. Barnett, 1998: Interdecadal modulation of ENSO teleconnections. Bull. Amer. Meteor. Soc., 79, 27152725 .

Gutzler, D. S., and J. W. Preston, 1997: Evidence for a relationship between spring snow cover in North American and summer rainfall in New Mexico. Geophys. Res. Lett., 24, 2207-2210.

Hales, J. E., 1972: Surges of maritime tropical air northward over the Gulf of California. Mon. Wea. Rev., 100, 298-306.

Harrington, J. A., R. S. Cerveny, and R. C. Balling, 1992: Impact of the Southern Oscillation on the North American monsoon. Phys. Geogr., 13, 318-330.

Higgins, R. W., and W. Shi, 2000: Dominant factors responsible for interannual variability of the summer monsoon in the southwestern United States. J. Climate, 13, 759-775.

— , Y. Yao, E. S. Yarosh, J. E. Janowiak, and K. C. Mo, 1997a: Influence of the Great Plains low-level jet on summertime precipitation and moisture transport over the central United States. J. Climate, 10, 481-507.

— _ - and X. L. Wang, 1997b: Influence of the North American monsoon system on the U.S. summer precipitation regime. $J$. Climate, 10, 2600-2622.

_ K. K. Mo, and Y. Yao, 1998: Interannual variability of the U.S. summer precipitation regime with emphasis on the southwestern monsoon. J. Climate, 11, 2582-2606.

_, Y. Chen, and A. V. Douglas, 1999: Interannual variability of the North American warm season precipitation regime. J. Climate, 12, 653-680.

Hirschboeck, K. K., 1999: Climate diagnostics of flooding in Arizona and implications for climatological forecasts of hydrologic extremes. Proc. 24th Annual Climate Diagnostics and Prediction Workshop, Tucson, AZ, NOAA/Climate Prediction Center and the Institute for the Study of Planet Earth and Institute for Atmospheric Physics, The University of Arizona, 367-370.

Horel, J. D., and J. M. Wallace, 1981: Planetary-scale atmospheric phenomena associated with the Southern Oscillation. Mon. Wea. Rev., 109, 813-829.

Kalnay, E., and Coauthors, 1996: The NCEP/NCAR 40-Year Reanalysis Project. Bull. Amer. Meteor. Soc., 77, 437-471.

Lau, N. C., and M. J. Nath, 1996: The role of the "atmospheric bridge" in linking tropical Pacific ENSO events to extratropical SST anomalies. J. Climate, 9, 2036-2037.

Liu, A. Z., M. Ting, and H. Wang, 1998: Maintenance of circulation anomalies during the 1988 drought and 1993 floods over the United States. J. Atmos. Sci., 55, 2810-2832.
Livezey, R. E., and W. Y. Chen, 1983: Statistical field significance and its determination by Monte Carlo techniques. Mon. Wea. Rev., 111, 46-59.

_ , and K. C. Mo, 1987: Tropical-extratropical teleconnections during the Northern Hemisphere winter. Part II: Relationships between monthly mean Northern Hemisphere circulation patterns and proxies for tropical convection. Mon. Wea. Rev., 115, $3115-3132$.

Mantua, N. J., S. R. Hare, U. Zhang, J. M. Wallace, and R. C. Francis, 1997: A Pacific interdecadal climate oscillation with impacts on salmon production. Bull. Amer. Meteor. Soc., 78, 1069-1079.

McKee, T. B., N. J. Doesken, and J. Kleist, 1999: Historical dry and wet periods in Colorado. Climatology Rep. 99-1, Part A: Technical Report, Department of Atmospheric Science, Colorado State University, $121 \mathrm{pp}$.

Meehl, G. A., 1994: Influence of the land surface in the Asian summer monsoon: External conditions versus internal feedbacks. J. Climate, 7, 1033-1049.

- , and Coauthors, 2000: An introduction to trends in extreme weather and climate events: Observations, socioeconomic impacts, terrestrial ecological impacts, and model projections. Bull. Amer. Meteor. Soc., 81, 413-416.

Minobe, S., 1997: A 50-70 year climatic oscillation over the North Pacific and North America. Geophys. Res. Lett., 24, 683-686.

Mo, K. C., J. N. Paegle, and R. W. Higgins, 1997: Atmospheric processes associated with summer floods and droughts in the central United States. J. Climate, 10, 3028-3046.

Nakamura, H., G. Lin, and T. Yamagata, 1997: Decadal climate variability in the North Pacific during the recent decades. Bull. Amer. Meteor. Soc., 78, 2215-2225.

Newman, M., and P. D. Sardeshmukh, 1998: The impact of the annual cycle on the North Pacific/North American response to remote low-frequency forcing. J. Atmos. Sci., 55, 1336-1353.

Nitta, T., and S. Yamada, 1989: Recent warming of tropical sea surface temperature and its relationship to the Northern Hemisphere circulation. J. Meteor. Soc. Japan, 67, 375-383.

Okabe, I. T., 1995: The North American monsoon. Ph.D. dissertation, University of British Columbia, $146 \mathrm{pp}$.

Rasmussen, E. M., 1967: Atmospheric water vapor transport and the water balance of North America. Part I: Characteristics of the water vapor flux field. Mon. Wea. Rev., 95, 403-427.

Reitan, C. H., 1957: The role of precipitable water in Arizona's summer rains. Tech. Rep. on the Meteorology and Climatology of Arid Regions 2, Institute of Atmospheric Physics, The University of Arizona, $19 \mathrm{pp}$.

Reyes, S., and A. Mejía-Trejo, 1991: Tropical perturbations in the eastern Pacific and the precipitation field over north-western Mexico in relation to the ENSO phenomenon. Int. J. Climatol., 11, 515-528.

Reynolds, R. W., and T. M. Smith, 1994: Improved global sea surface temperature analyses using optimum interpolation. J. Climate, 7, 929-948.

Ropelewski, C. F., and M. S. Halpert, 1986: North American precipitation and temperature patterns associated with the El Niño/ Southern Oscillation (ENSO). Mon. Wea. Rev., 114, 2352-2362.

Schmitz, J. T., and S. Mullen, 1996: Water vapor transport associated with the summertime North American monsoon as depicted by ECMWF analyses. J. Climate, 9, 1621-1634.

Slutz, R. J., S. J. Lubker, J. D. Hiscox, S. D. Woodruff, R. L. Jenne, D. H. Joseph, P. M. Stehrer, and J. D. Elms, 1985: Comprehensive Ocean Atmosphere Data Set; Release 1. Climate Research Program, NOAA/Environmental Research Laboratories, Boulder, $\mathrm{CO}, 268 \mathrm{pp}$.

Sud, Y. C., K. M. Lau, G. K. Walker, and J. H. Kim, 1995: Understanding biosphere-precipitation relationships: Theory, model simulations, and logical inferences. Mausam, 46, 1-14.

Tang, M., and E. R. Reiter, 1984: Plateau monsoons of the Northern Hemisphere: A comparison between North America and Tibet. Mon. Wea. Rev., 112, 617-637.

Ting, M., and H. Wang, 1997: Summertime U.S. precipitation vari- 
ability and its relation to Pacific sea surface temperature. J. Climate, 10, 1853-1873.

Trenberth, K. E., and G. W. Branstator, 1992: Issues in establishing causes of the 1988 drought over North America. J. Climate, 5, $159-172$.

_- - and C. J. Guillemot, 1995: Evaluation of the global atmospheric moisture budget at seen from analyses. J. Climate, 8 , 2255-2272.
— drought and 1993 floods in North America. J. Climate, 9, 12881298.

Wilks, D. S., 1995: Statistical Methods in the Atmospheric Sciences. Academic Press, 467 pp.

Zhang, Y., J. M. Wallace, and D. S. Battisti, 1997: ENSO-like interdecadal variability: 1900-93. J. Climate, 10, 1004-1020. 